\title{
Nordic \\ Green \\ to Scale
}

Nordic climate

solutions can help

other countries

cut emissions

(1) Nordic Council of Ministers 
Nordic Green to Scale

Nordic low-carbon success stories to inspire the world

Editor: Oras Tynkkynen (Sitra)

Technical analysis: Jan Ivar Korsbakken and Borgar Aamaas (CICERO)

ISBN 978-92-893-4734-1 (PRINT)

ISBN 978-92-893-4735-8 (PDF)

http://dx.doi.org/10.6027/ANP2016-776

ANP 2016:776

(C) Nordic Council of Ministers 2016

Layout: Nórr Design

Cover Photo: norden.org

Photos: norden.org, istockphoto.com, pexels.com

Print: Rosendahls

Copies: 750

Type: Mark Pro

Paper: MultiDesign White

Printed in Denmark

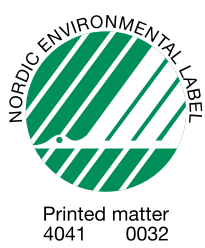

This publication has been published with financial support by the Nordic Council of Ministers. However, the contents of this publication do not necessarily reflect the views, policies or recommendations of the Nordic Council of Ministers.

\section{www.norden.org/nordpub}

\section{Nordic co-operation}

Nordic co-operation is one of the world's most extensive forms of regional collaboration, involving Denmark, Finland, Iceland, Norway, Sweden, and the Faroe Islands, Greenland, and Åland.

Nordic co-operation has firm traditions in politics, the economy, and culture. It plays an important role in European and international collaboration, and aims at creating a strong Nordic community in a strong Europe.

Nordic co-operation seeks to safeguard Nordic and regional interests and principles in the global community. Shared Nordic values help the region solidify its position as one of the world's most innovative and competitive.

\section{Nordic Council of Ministers}

Ved Stranden 18

DK-1061 Copenhagen $\mathrm{K}$

Phone (+45) 33960200 


\section{Contents}

From commitment to action

Executive Summary

Introduction

Results: Emissions, Costs and Benefits $\quad 10$

$\begin{array}{ll}\text { Discussion } & 19\end{array}$

$\begin{array}{ll}\text { Methodology } & 23\end{array}$

$\begin{array}{ll}\text { Project Background } & 27\end{array}$

$\begin{array}{ll}\text { Solutions Catalogue } & 28\end{array}$

Energy $\quad 31$

Combined heat and power production $\quad 32$

Onshore wind power $\quad 34$

Offshore wind power $\quad 36$

Geothermal power $\quad 38$

$\begin{array}{ll}\text { Industry } & 41\end{array}$

Carbon capture and storage in oil and gas production $\quad 42$

Reducing methane in oil and gas production $\quad 44$

Low-carbon energy in industry $\quad 46$

$\begin{array}{ll}\text { Transport } & 49\end{array}$

Electric vehicles $\quad 50$

Biofuels in transport $\quad 52$

Cycling in cities $\quad 54$

Buildings and Households $\quad 57$

Energy efficiency in buildings $\quad 58$

$\begin{array}{ll}\text { Residential heat pumps } & 60\end{array}$

$\begin{array}{ll}\text { Bioenergy for heating } & 62\end{array}$

$\begin{array}{ll}\text { Agriculture and Forests } & 65\end{array}$

Reforestation and land restoration $\quad 66$

$\begin{array}{ll}\text { Manure management } & 68\end{array}$ 



\section{PREFACE:}

\section{From commitment to action}

2015 WAS A YEAR of commitments. First in New York world leaders adopted new Sustainable Development Goals to rid the world of poverty, improve health, protect our environment and work through partnerships. Later in Paris countries agreed on the historic Paris climate agreement inspiring emission reduction commitments from virtually all nations. These efforts are intrinsically linked.

From now on every year has to be a year of action. To achieve the goals set in the Paris agreement - to limit global warming to well below $2^{\circ} \mathrm{C}$ and pursue efforts to keep it at just $1.5^{\circ} \mathrm{C}$ - countries need to ramp up their climate efforts significantly. And we need to do it fast.

That is why this study is so important. Like the global Green to Scale report released last year, this Nordic study shows that there are already plenty of proven low-carbon solutions available, and at an affordable cost. There is no reason to wait. The time to deliver is now.

As citizens of a Nordic country, we are proud of the role our region can play. By helping the world in scaling up these solutions, Nordic countries can contribute to tackling the climate crisis way beyond our size. And yet we are humbled by the fact that we, too, need to do much more to meet our existing commitments and go beyond them.

This report is also an appeal to all of you. How can we inspire and encourage more action? What role can you play?

We know it can be done. Now let us take action - together.

\section{Kimmo Tiilikainen}

Minister of Agriculture

and the Environment of

Finland

\section{Mikko Kosonen}

President

Sitra, the Finnish

Innovation Fund 


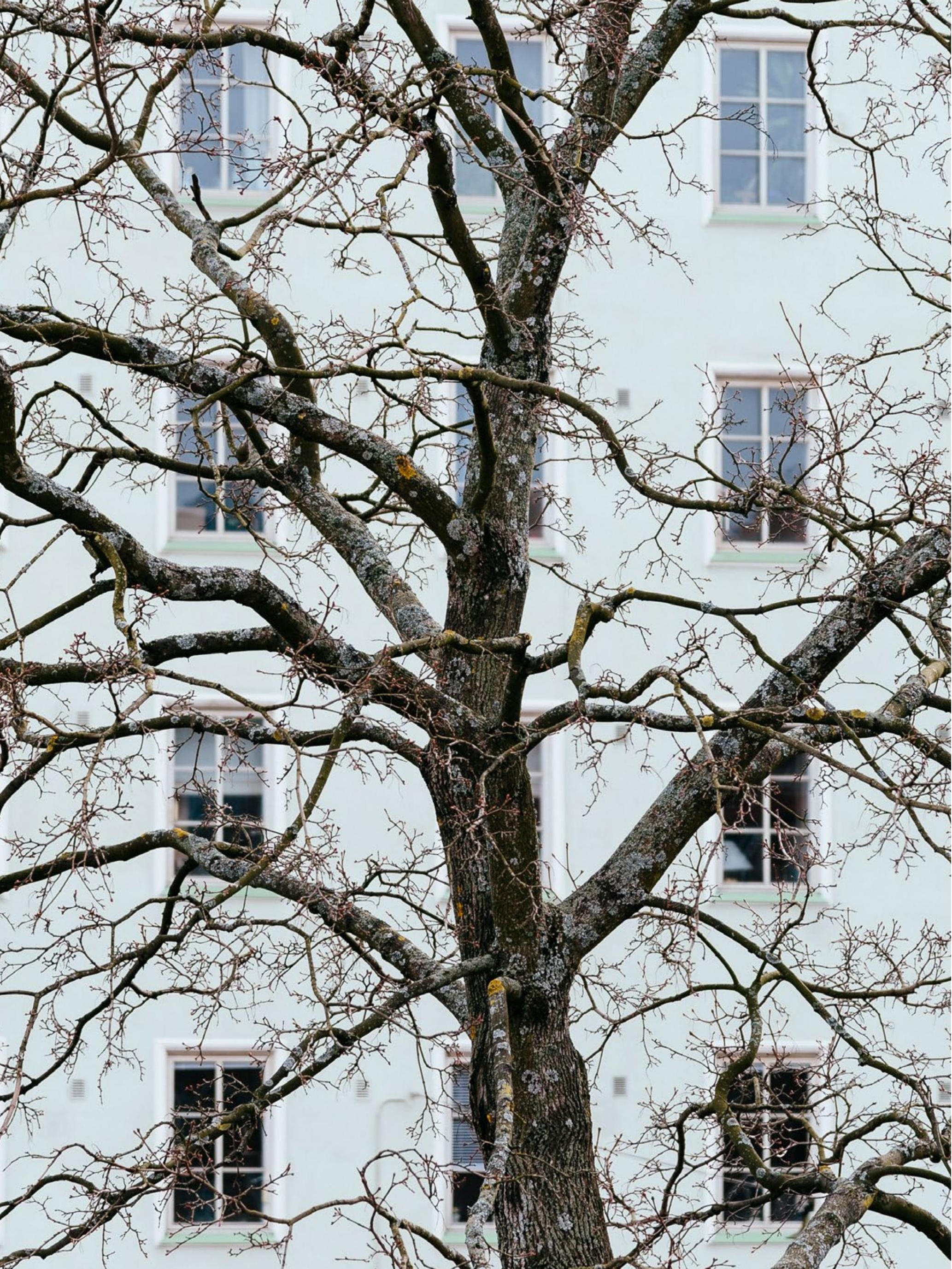




\section{Executive Summary}

\section{Introduction}

To keep global warming well below $2^{\circ} \mathrm{C}$, countries need to both meet their existing emission targets and go beyond them. The Nordic Green to Scale project helps in choosing the concrete low-carbon solutions to do so.

The study looks at 15 existing climate solutions that have been proven to work in the Nordic region. We have estimated the climate impact and costs of scaling them up to other countries. We have also looked at co-benefits of and barriers to these solutions, as well as policies to promote them.

\section{The 15 solutions}

The low-carbon solutions were selected mainly based on four criteria: 1) Nordic distinctiveness, 2) proven climate impact, 3) analysis feasibility, and 4) scalability. The project also strived to maintain a reasonable geographical and sectoral balance.

Many more Nordic solutions already exist that could contribute to reducing global emissions. There are still more solutions that are currently being developed or in the early stages of implementation.

\section{Climate impact}

Scaling up the selected Nordic solutions can cut global emissions by 4.1 gigatonnes $\left(\mathrm{GtCO}_{2} \mathrm{e}\right)$ in 2030 . The reduction is equal to the current total emissions of the European Union.

The climate impact varies greatly between solutions. The solution with the largest potential is combined heat and power production, which alone could reduce emissions by almost as much as Japan produces every year.

Table 1: Key results in 2030

\section{Scaling up just 15 Nordic solutions can cut global emissions by 4 gigatonnes in 2030.}

\begin{tabular}{|c|c|c|c|c|}
\hline & Solution & Reference countries & $\begin{array}{r}\text { Reduction } \\
\left(\mathrm{MtCO}_{2} \mathrm{e}\right)\end{array}$ & $\begin{array}{r}\text { Costs } \\
\text { (billion \$) }\end{array}$ \\
\hline \multirow{4}{*}{ Energy } & Combined heat and power production & Denmark, Finland & 1,171 & -7.7 \\
\hline & Onshore wind power & Denmark, Sweden & 695 & 16.9 \\
\hline & Offshore wind power & Denmark & 22 & 0.8 \\
\hline & Geothermal power & Iceland & 55 & 0.3 \\
\hline \multirow{3}{*}{ Industry } & Carbon capture and storage in oil and gas production & Norway & 63 & 2.1 \\
\hline & Reducing methane in oil and gas production & Norway & 357 & -5.1 \\
\hline & Low-carbon energy in industry & Finland, Sweden & 57 & 1.3 \\
\hline \multirow{3}{*}{ Transport } & Electric vehicles & Norway & 50 & 6.0 \\
\hline & Biofuels in transport & Finland, Sweden & 423 & 0.8 \\
\hline & Cycling in cities & Denmark & 37 & -1.6 \\
\hline \multirow{3}{*}{$\begin{array}{l}\text { Buildings and } \\
\text { households }\end{array}$} & Energy efficiency in buildings & Sweden & 430 & -8.6 \\
\hline & Residential heat pumps & Sweden & 64 & -3.1 \\
\hline & Bioenergy for heating & Finland & 193 & 7.7 \\
\hline \multirow{3}{*}{$\begin{array}{l}\text { Agriculture } \\
\text { and forests }\end{array}$} & Reforestation and land restoration & Iceland & 21 & 0.3 \\
\hline & Manure management & Denmark & 478 & 2.4 \\
\hline & & Total & 4,117 & 12.6 \\
\hline
\end{tabular}




\section{More can be done}

Overall, the analysis is likely to be conservative. The solutions are applied by 2030 only to the extent the Nordic countries have already achieved today, for example.

The full potential is likely to be larger. Other countries may go further by 2030 than the Nordic countries have achieved today. Existing solutions will develop further, and new solutions will emerge. Countries implementing policies today can benefit from the experiences of the past, thus enabling better results faster.

In addition, implementation can be coupled with innovation. This makes existing solutions even more effective and affordable. It also provides completely new solutions - solutions that are desperately needed to reach zero and later net negative emissions.

\section{Economic rationale}

The net cost of implementing all 15 solutions is estimated to be $\$ 13$ billion in 2030 . To put the number into perspective, the cost of scaling up the solutions would equal what countries globally spend on fossil fuel subsidies in just nine days.

Behind the net total costs are large differences between the solutions. Onshore wind comes with an estimated price tag of $\$ 17$ billion. On the other hand, energy efficiency in buildings could save nearly $\$ 9$ billion.

The average net abatement cost is $3 \$ / \mathrm{tCO}_{2} \mathrm{e}$ in 2030. This is just half of the current price of allowances in the EU emissions trading system - and much less than the projected prices in 2030.

The costs do not include co-benefits such as improved health or ecosystem services. If full benefits were included, the solutions would be significantly cheaper - in some cases turning costs into savings.

\section{Co-benefits}

Most solutions have various co-benefits. Positive effects include improvements in health, employment and ecosystem services. For example, encouraging people to bike more can help cut harmful air pollution and noise, reduce traffic congestion, improve health and free up urban space for other uses.

\section{Barriers and policies}

Attractive low-carbon solutions are being held back by various barriers. First, many solutions require a significant up-front investment. Second, low-carbon options suffer from fossil fuel subsidies and low energy prices. Third, lack of awareness and public opposition may hamper progress. Finally, low-carbon solutions can have negative social or environmental impacts, if planned or implemented poorly.

Countries can remove these barriers by learning from the countries that have already done so. Some conclusions can be drawn from the 15 analysed Nordic solutions.

First, there needs to be an incentive to reduce emissions through pricing carbon, for instance. Second, mandates and norms still play a role. Third, clear targets and a predictable regulatory environment enable investments. Fourth, providing information and raising awareness can facilitate action. Finally, climate action also needs to be socially and environmentally sustainable.

\section{Conclusion}

This study shows that simply using what we already have can take us a long way in tackling the climate crisis, building on the Nordic experience. Countries around the world have a range of proven and attractive low-carbon solutions to choose from.

There is no need to wait. And, more importantly, there is no time to wait. The time for climate action is now.

\section{The net cost of implementing all 15 solutions is estimated to be $\$ 13$ billion in 2030. This equals the amount that countries globally spend on fossil fuel subsidies in just nine days.}




\section{Introduction}

AFTER THE ADOPTION of the Paris Agreement, the world faces two tasks. First, countries need to implement their current climate commitments. Second, they must explore going beyond them to bridge the emissions gap between current pathways and those in line with the temperature goals of the Paris Agreement.

The Nordic Green to Scale project helps countries in meeting these challenges. The basic concept is simple. The study looks at 15 existing climate solutions that have been implemented at scale and proven to work successfully in the Nordic region. We have then scaled up these solutions to applicable countries elsewhere and estimated their impact on global emissions, costs and benefits to society.

The international Green to Scale project conducted in 2015 showed that scaling up just 17 low-carbon solutions could reduce global emissions by 12 gigatonnes of carbon dioxide equivalent $\left(\mathrm{GtCO}_{2} \mathrm{e}\right)$ by 2030 . Now the Nordic follow-up project builds on this analysis and expands it.

Numerous studies before have identified significant potential for further climate action. What makes Green to Scale stand out is its unique approach.

Instead of relying on emerging technologies and theoretical scenarios, the study focuses simply on what we have today: existing low-carbon solutions with a proven track record. Instead of pushing countries into uncharted territories, the analysis expects them to reach by 2030 the same level some other countries have already achieved today.

The approach is in many ways conservative. By 2030, many countries can go beyond what the Nordic countries have achieved today. Over the coming years, low-carbon technologies will continue to become cheaper and more effective. Countries implementing policies today can benefit from the experiences of the past.

\section{The Nordic Green to Scale project looks at 15 existing climate solutions that have been proven to work successfully in the Nordic region.}

While many low-carbon solutions are already attractive, they are being held back by various barriers. That is why we also look at the success stories of the Nordic countries and how they have been able to overcome these barriers.

This and the previous Green to Scale study clearly illustrate that countries have a range of proven and attractive low-carbon solutions to choose from. By working together, we can move further, tackle the climate crisis and reap the benefits of green growth.

Over time, we can create a snowball effect in which countries learn from, and are inspired by, each other's efforts and successes. Eventually we will - hopefully - arrive at a level of action that is enough to achieve the ambitious climate goals of the Paris Agreement.

This editorial report presents the key findings and relevant background information of the Nordic Green to Scale study in a concise form. For further information, please refer to the full technical report available online at www.greentoscale.net/nordic. 


\section{Results: Emissions, Costs and Benefits}

\section{Climate impact}

Scaling up existing low-carbon solutions can reduce global emissions significantly. Our analysis shows that just 15 Nordic solutions can save 4.1 gigatonnes of carbon dioxide equivalent $\left(\mathrm{GtCO}_{2} \mathrm{e}\right)$ in 2030, if implemented widely in comparable countries.

The emission reduction is equal to the total emissions of the European Union. It is also more than 20 times the current combined emissions of the five Nordic countries.

The full potential of existing solutions is higher. A larger number of solutions would reduce emissions even more. Countries may go further by 2030 than what the Nordic countries have achieved today. Existing solutions will develop further, and new solutions will emerge.

The largest potential identified in this study is in the energy sector. Combined heat and power (CHP), wind power and geothermal energy cover almost half of the total potential.

Five solutions are fully scaled up globally. At the other extreme, bioenergy for heating is applied only to three countries. Many solutions are expected to be implemented only in relatively wealthy countries, to make sure that the conditions are sufficiently comparable to the Nordic countries.
Figure 1: Emission reductions by sector

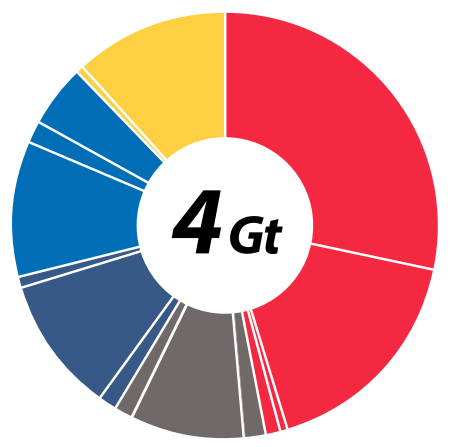

Energy (4)

Industry (3)

Transport (3)

Buildings and Households (3)

Agriculture and Forests (2)

Emission potentials in this study are presented with ranges, recognising uncertainties. At the higher end, 15 analysed solutions could deliver an emission reduction of $4.7 \mathrm{Gt}$, whereas under more pessimistic assumptions the impact could be $3.6 \mathrm{Gt}$. Taking into account possible overlap between different solutions reduces the impact by a little more than $0.1 \mathrm{Gt}$ in 2030.

\section{Scaling up existing low-carbon solutions can reduce global emissions significantly: just 15 Nordic solutions can save $4 \mathrm{Gt}$ in 2030, if implemented widely in comparable countries.}




\section{LOW-CARBON SOLUTIONS ARE AFFORDABLE}

In 2030, the cost of scaling up

15 Nordic solutions equals

9 days

of current global fossil fuel subsidies

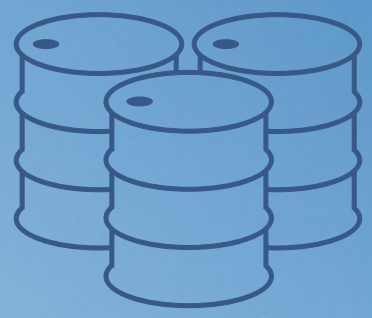

Direct fossil fuel subsidies in 2014 are \$493 billion

globally

CLIMATE SOLUTIONS CREATE CONSIDERABLE CO-BENEFITS
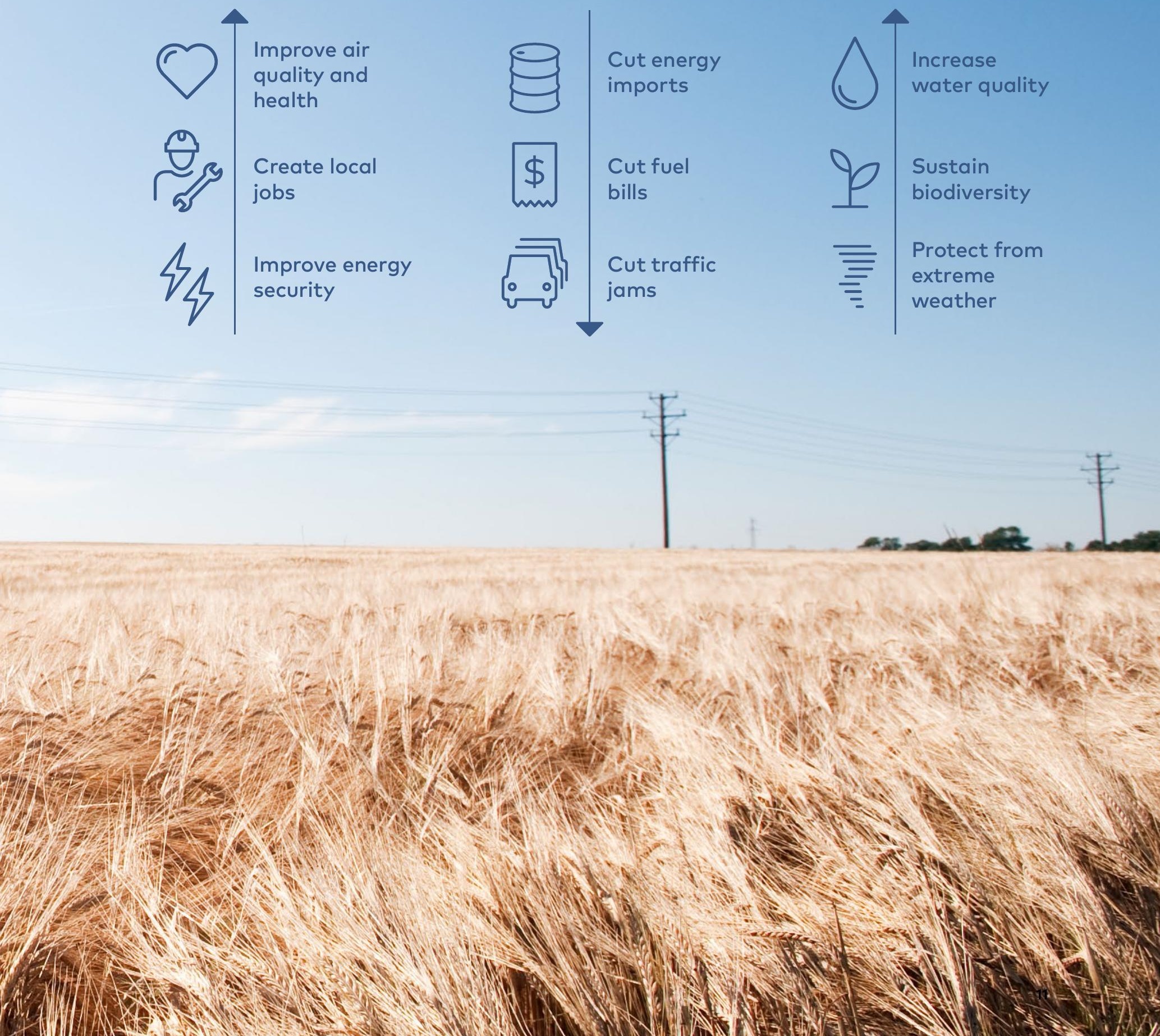


\section{Figure 2: Total climate potential of the solutions in 2030}

Combined heat and power production

Onshore wind power

Offshore wind power

Geothermal power

Carbon capture and storage in oil and gas production

Reducing methane in oil and gas production

Low-carbon energy in industry

Electric vehicles

Biofuels in transport

Cycling in cities

Energy efficiency in buildings

Residential heat pumps

Bioenergy for heating

Reforestation and land restoration

Manure management

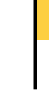

0

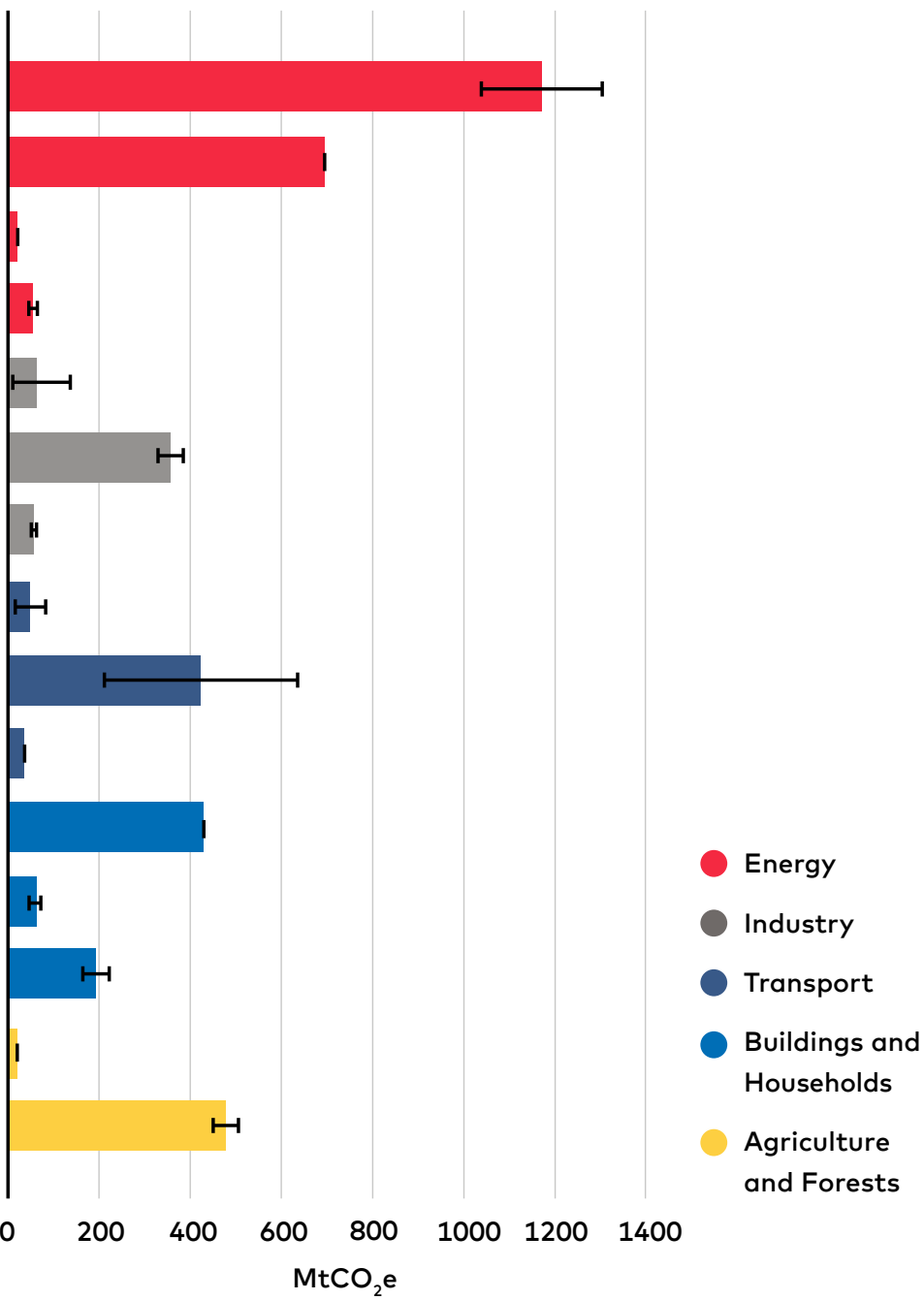

Coloured bars represent central values, black lines full ranges.

\section{Impact by solution}

The climate potential varies greatly between solutions, from as little as 20 megatonnes (Mt) to as much as $1,200 \mathrm{Mt}$. The solution with the largest potential is combined heat and power production, which alone could reduce emissions by almost as much as Japan produces every year.

Five other solutions can cut emissions by around $400 \mathrm{Mt}$ or more. These are onshore wind power, manure management, energy efficiency in buildings, biofuels in transport and reducing methane from oil and gas production.

The relatively small potentials for some solutions do not necessarily give a fair picture of their full promise. The numbers are based on scaling up what has actually been implemented in the Nordic countries already, relative to an expected global baseline of climate action for 2030 . The figures are not an assessment of the total technical or economic potential for any of the solutions.

For example, offshore wind results in modest emission reductions not because the potential itself is small, but because countries are investing heavily in the technology anyway. As the analysis only identifies the effect of scaling up what Nordic countries have already done, over and above what other countries are already planning to do, the impact can seem very small.

When comparing electric vehicles (EVs) and biofuels in transport, the abatement potential for biofuels is significantly larger. This is due to the fact that the degree of implementation (share of total fuel use in Sweden and Finland) is almost five times higher than for EVs in Norway (share of electricity in road transport energy). Biofuels are also scaled up to 
Table 2: Emission reduction impact of scaled-up solutions

\begin{tabular}{|c|c|c|c|c|c|c|}
\hline \multirow[t]{2}{*}{ Impact $\left(\mathrm{MtCO}_{2} \mathrm{e}\right)$} & \multicolumn{3}{|c|}{2025} & \multicolumn{3}{|c|}{2030} \\
\hline & Lower & Central & Upper & Lower & Central & Upper \\
\hline Combined heat and power production & 656 & 742 & 828 & 1,039 & 1,171 & 1,303 \\
\hline Onshore wind power & 579 & 579 & 579 & 695 & 695 & 695 \\
\hline Offshore wind power & 22 & 22 & 22 & 22 & 22 & 22 \\
\hline Geothermal power & 20 & 24 & 27 & 46 & 55 & 64 \\
\hline $\begin{array}{l}\text { Carbon capture and storage in oil } \\
\text { and gas production }\end{array}$ & 5 & 36 & 79 & 11 & 63 & 137 \\
\hline Reducing methane in oil and gas production & 200 & 216 & 233 & 329 & 357 & 384 \\
\hline Low-carbon energy in industry & 31 & 34 & 37 & 52 & 57 & 63 \\
\hline Electric vehicles & 7 & 46 & 84 & 17 & 50 & 83 \\
\hline Biofuels in transport & 100 & 200 & 300 & 212 & 423 & 635 \\
\hline Cycling in cities & 23 & 23 & 23 & 37 & 37 & 37 \\
\hline Energy efficiency in buildings & 280 & 280 & 280 & 430 & 430 & 430 \\
\hline Residential heat pumps & 12 & 19 & 22 & 47 & 64 & 72 \\
\hline Bioenergy for heating & 159 & 187 & 215 & 164 & 193 & 222 \\
\hline Reforestation and land restoration & 11 & 12 & 13 & 20 & 21 & 23 \\
\hline Manure management & 253 & 269 & 284 & 450 & 478 & 506 \\
\hline Total & 2,358 & 2,687 & 3,026 & 3,571 & 4,117 & 4,676 \\
\hline Total minus overlaps & 2,313 & 2,634 & 2,965 & 3,455 & 3,980 & 4,519 \\
\hline
\end{tabular}

Figures in $\mathrm{MtCO}_{2} \mathrm{e}$. The range reflects different assumptions and uncertainties.

all road transport globally, while EVs are only applied to personal vehicles in a smaller geographical region.

Another example is reforestation and land restoration. Scaling up the Icelandic level of achievement would not make a big dent on global emissions. However, this is more due to the fact that Iceland itself still has a long way to go. The full potential in the target regions would be a staggering 1.8 $\mathrm{Gt}$ - and the global potential even larger.

Moreover, while some solutions may only address climate change to a limited extent, they may provide many other benefits. Promoting cycling in cities, following the example of Denmark, would save money, reduce congestion and improve health, for example.

\section{The Finnish Innovation Fund Sitra partnered with the Nordic Council of Ministers and distinguished institutions from all Nordic countries to produce this study.}


Figure 3: Total abatement cost for the solutions in 2030

Combined heat and power production

Onshore wind power

Offshore wind power

Geothermal power

Carbon capture and storage in oil and gas production

Reducing methane in oil and gas production

Low-carbon energy in industry

Electric vehicles

Biofuels in transport

Cycling in cities

Energy efficiency in buildings

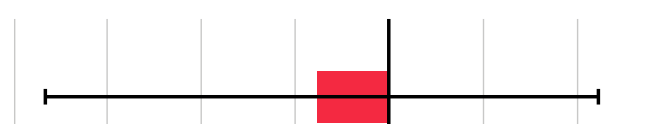

Residential heat pumps

Bioenergy for heating

Reforestation and land restoration

Manure management

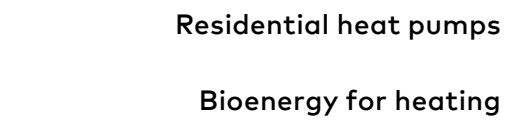

$-40$

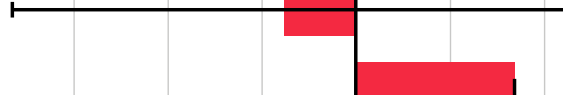

Energy

Industry

Transport

Buildings and

Households

Agriculture

and Forests

Billion \$

Coloured bars represent central values, black lines full ranges.

\section{Total costs and savings}

The net cost of implementing all 15 solutions (after subtracting direct savings) is estimated to be approximately $\$ 13$ billion in 2030 . Onshore wind comes with a price tag of $\$ 17$ billion. On the other hand, energy efficiency in buildings could save money by nearly $\$ 9$ billion.

To put the costs into perspective, the world spent in 2014 almost half a trillion US dollars in direct fossil fuel subsidies - and many times more on indirect subsidies. Therefore, the costs of scaling up 15 Nordic low-carbon solutions would equal what countries spend on making fossil fuels more attractive in just nine days.

It is important to note that the costs in our analysis do not include co-benefits such as improved health or ecosystem services. If full co-benefits were included, the costs of the solutions would be significantly lower - in some cases turning costs into savings.

\section{Costs and savings by solution}

There is large variation in the costs of the solutions. The abatement cost - the cost it takes to reduce a tonne of emissions with the solution - can be as high as $100 \$ / \mathrm{tCO}_{2}$ e or more. At the other extreme, implementing a solution can save $\$ 50$ for each tonne of emissions reduced.

The average net abatement cost is just $3 \$ / \mathrm{tCO}_{2} \mathrm{e}$ in 2030. This is just half of the current price of emission allowances in the EU emissions trading system - and much less than the projected prices in 2030. It is also considerably lower than the so-called social cost of carbon - the full costs of climate change caused by each tonne of emissions.

Out of the 15 solutions, five have negative net costs, in other words they save money. The most profitable solutions save energy, either directly or indirectly. For most solutions the costs fall in the range $0-50 \$ / \mathrm{tCO}_{2} \mathrm{e}$. 


\section{Figure 4: Unit abatement cost for the solutions in 2030}

Combined heat and power production

Onshore wind power

Offshore wind power

Geothermal power

Carbon capture and storage in oil and gas production

Reducing methane in oil and gas production

Low-carbon energy in industry

Electric vehicles

Biofuels in transport

Cycling in cities

Energy efficiency in buildings

Residential heat pumps

Bioenergy for heating

Reforestation and land restoration

Manure management

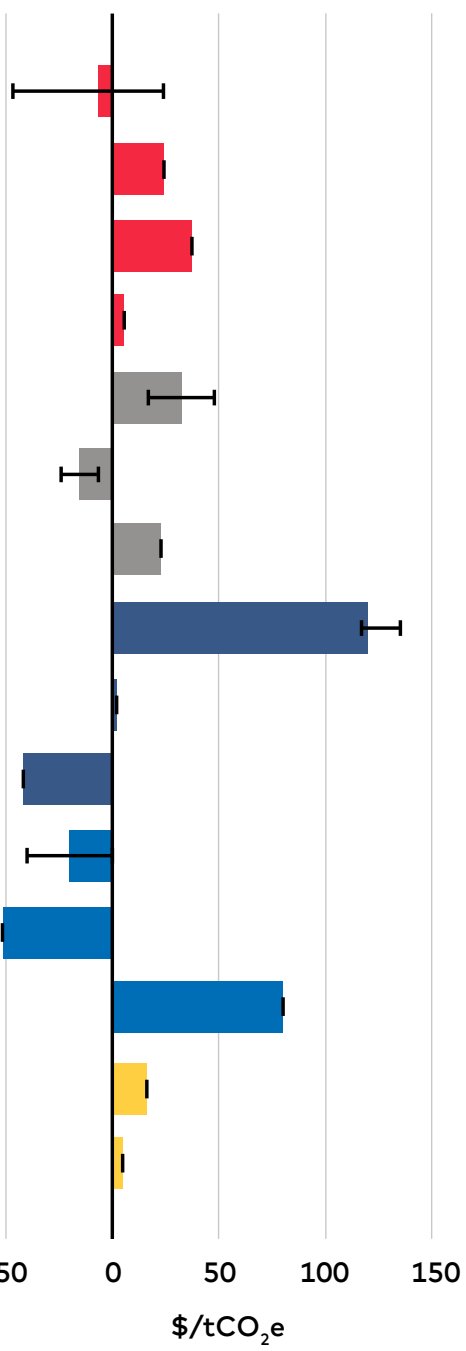

Energy

Industry

Transport

Buildings and

Households

Agriculture

and Forests

$\$ / \mathrm{tCO}_{2} \mathrm{e}$

Coloured bars represent central values, black lines full ranges.

The most expensive solution per a tonne of emissions reduced is electric vehicles (EVs). Even though it is cheaper to drive an EV than a conventional car, buying the vehicle still comes at a considerable premium. As prices of batteries fall and sales of EVs increase, this may change.

\section{Benefits to people and the environment}

Most analysed solutions have various co-benefits, apart from the obvious climate impact and economic savings. Positive effects include improvements in health, employment and ecosystem services.

Possibly the most attractive solution from the point of view of co-benefits is cycling in cities. Encouraging people to cycle more cuts harmful air pollution and noise, reduces traffic congestion, improves health and frees up urban space for other uses.
Solutions increasing the use of renewable energy and improving energy efficiency in most cases reduce fuel imports and improve energy security. If the solution relies largely on domestic technology and work, it can also improve the balance of trade and create local jobs.

Solutions reducing the use of fossil fuels in energy and transport cut harmful air pollution. Electric vehicles also reduce noise pollution, whereas manure management helps in reducing water pollution. Reforestation and land restoration can support multiple ecosystem services, such as preventing erosion, protecting from extreme weather and sustaining biodiversity.

Improving energy efficiency in buildings can increase housing quality by reducing draft and exposure to noise. Better designs and materials 
applied to reduce methane emissions in oil and gas production may also relate to better safety, employee health and productivity.

While most low-carbon solutions provide multiple co-benefits to people and the environment, an exception to the rule is carbon capture and storage (CCS). The technology analysed in this study is motivated by climate benefits alone.

\section{Removing the barriers}

This report confirms the message from many studies before: there are various existing and proven low-carbon solutions available. Moreover, they are attractive and affordable.

But if these solutions are so good, why, then are they not being implemented on a larger scale? What is holding us back?

Implementation often faces several barriers. Looking at these 15 Nordic solutions, we can recognise four particular challenges common to many countries and cases.

First, while many solutions are affordable in the long run or may even save money, they often require a significant up-front investment. Second, low-carbon options suffer from fossil fuel subsidies and low energy prices. Third, lack of awareness and even public opposition may hamper progress. Finally, low-carbon solutions can also have negative social or environmental impacts, if planned or implemented poorly.

These and other barriers slow down climate action and prevent us from seizing the full potential of existing low-carbon solutions. Luckily, we can remove barriers by learning from the successes of countries that have already done so. The 15 Nordic cases described in this report provide useful lessons for some, while the 17 cases in the earlier global Green to Scale study can help many others.

Concrete measures will vary from one country and solution to another. However, some general conclusions can be drawn.

First, there needs to be a strong economic incentive to reduce emissions. Pricing carbon either through taxes or trading is one key tool, cutting fossil fuel subsidies is another.

Second, mandates and norms still play a role. Setting minimum requirements can level the playing field and ensure implementation in cases where financial incentives may not be enough.

Third, clear targets and a predictable regulatory environment enable investments. Public authorities can also help by certifying, testing and setting standards, thus creating a framework for functioning markets.

Fourth, providing information and raising awareness can facilitate action without regulatory burden or high costs. Support for research, development and demonstration (R\&D\&D) forms a basis for improving existing solutions further - and creating completely new ones.

Finally, climate action also needs to be socially and environmentally sustainable. Introducing robust sustainability safeguards, sharing the benefits of lowcarbon investments with local people and involving citizens in decision-making can help in securing public acceptance.

\section{This report confirms that there are various existing and proven low-carbon solutions available. Moreover, they are attractive and affordable.}




\section{Emerging Nordic solutions}

The Green to Scale project focuses on a selection of existing solutions only. To qualify, a solution must have a proven track record of being implemented at significant scale for some time.

This and other studies show that simply using what we already have can take us a long way in tackling the climate crisis. However, various emerging solutions are likely to make reducing emissions easier, cheaper and faster.

1. Energy. In Norway, Statoil has piloted floating wind farms. In Finland, a demonstration project called DeepHeat plans to use the geothermal energy buried kilometres underground for heating the city of Espoo. Denmark is integrating largescale solar collectors to district heating systems.

2. Industry. Apart from oil and gas production, Norway has built carbon capture and storage facilities also in the production of fertilisers and cement as well as waste incineration. Iceland already captures $\mathrm{CO}_{2}$ and stores it in basaltic rock. The Swedish metal processing industry invests in research and development for radical innovations to reduce process emissions.
3. Transport. Sweden is piloting electric highways that would allow trucks to switch to electricity. Finnish company Neste is providing biofuels for aeroplanes and other companies are producing advanced biofuels out of cellulosic residues. Norway has introduced electric ferries.

4. Buildings and households. Many Nordic countries have examples of net-zero houses - or even buildings that produce more energy than they consume. Smart homes let people monitor and control their energy use better, simultaneously saving energy.

5. Agriculture and forests. Several Swedish and Finnish companies are producing plant-based alternatives to more carbon-intensive meat and dairy products. A Norwegian project is piloting the production of ocean biomass and at the same time storing carbon.

These and many other examples illustrate the wide range of activity on low-carbon innovation in the Nordic countries. If we were to replicate the Green to Scale analysis in 5-10 years, some of the emerging solutions might have become proven, making it again easier to reduce emissions. 


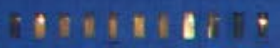

$2^{2}$

$1151,1911,4$

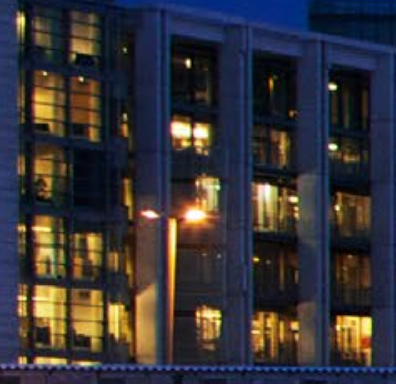

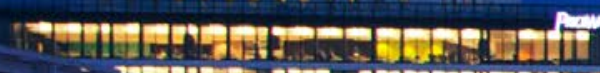

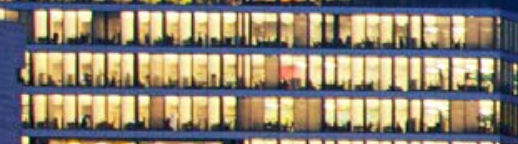

atis

- Ean?

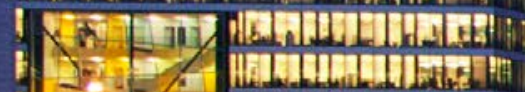

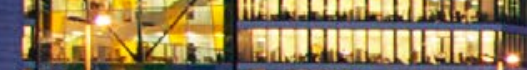

1 लिifis:

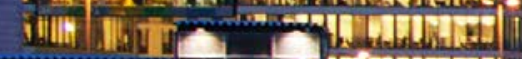
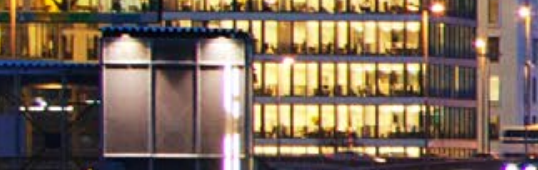

$1+3$

$\Delta, \Delta \Delta$

int... F*

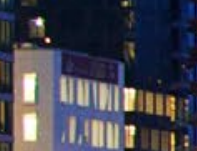

ㄱ.

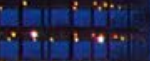

incito 40

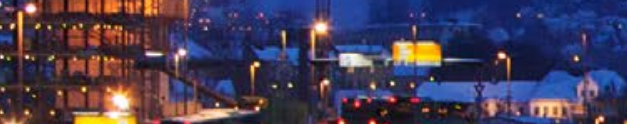

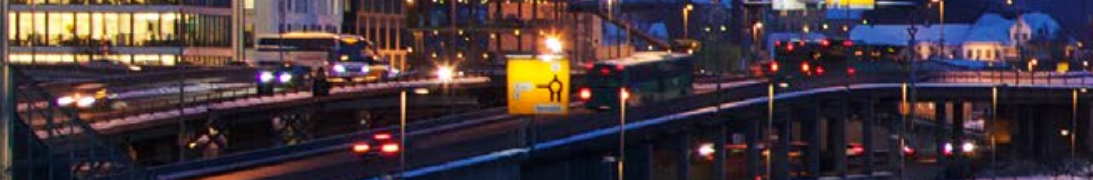

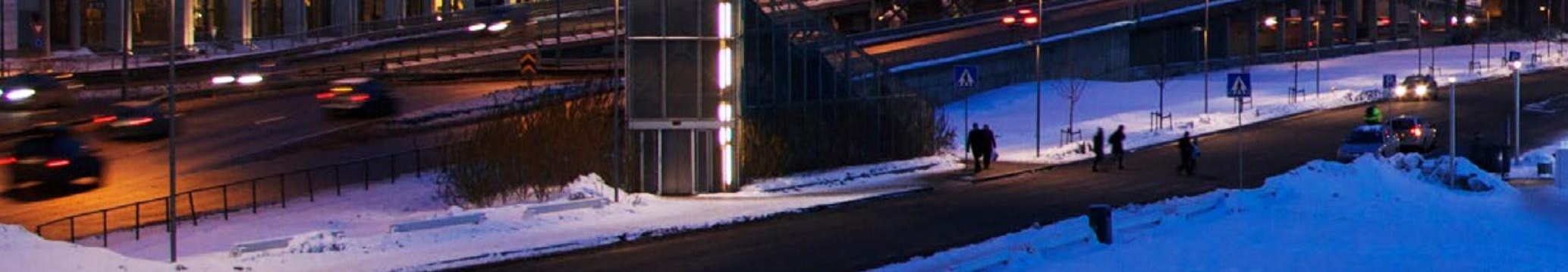

$1+\left.\right|_{0}$

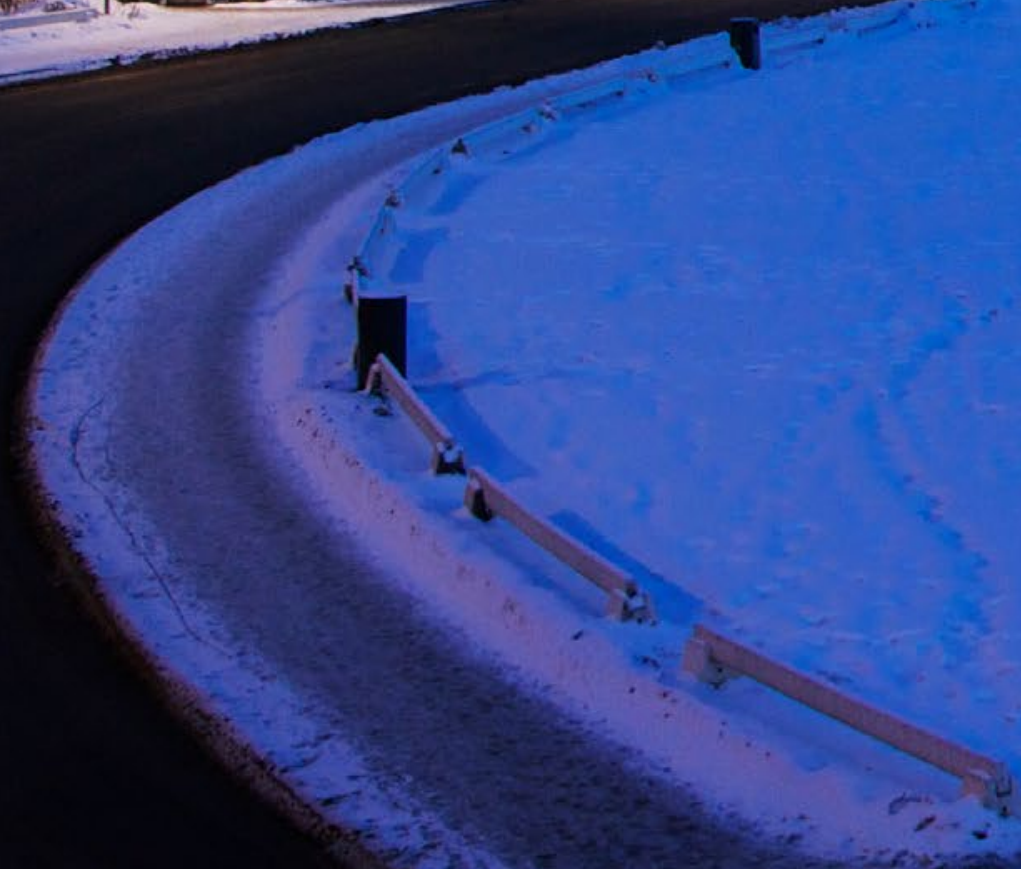




\section{Discussion}

\section{Why these solutions?}

The solutions were selected by the project steering group primarily based on four criteria: Nordic distinctiveness, proven impact, analysis feasibility, and scalability. The project also strived to maintain a reasonable balance between the five Nordic countries and solution categories.

There are many more existing Nordic solutions that could contribute to reducing global emissions. These include cutting food waste, introducing biogas buses, practicing sustainable forestry and replacing fuels with electricity in processing plants. Some more systemic measures, such as the Nordic electricity market and emission-based taxation, were excluded because it would have been difficult to estimate their impact.

There are still more solutions that are currently being developed or in the early stages of implementation. These include electric and gas-powered shipping, novel solutions for carbon capture and storage and cutting nitrous oxide emissions from fertilizer production.

\section{Are Nordic solutions applicable elsewhere?}

The Nordic countries are not representative of the whole world as they generally have more developed economies, higher institutional capacities and larger renewable resources. However, many of the experiences can be applicable in many other countries for various reasons.

First, while no other country is identical to their Nordic counterparts, many countries share many

\section{There are many more existing Nordic solutions that could contribute to reducing global emissions.}

similarities. OECD countries, for example, have comparable levels of economic development - and some OPEC countries even higher GDP per capita than some Nordic countries.

Second, many of the solutions analysed in this study are if not universal, at least versatile enough to be used in different circumstances. Alongside Denmark and Sweden, also countries like China, Brazil and India are investing heavily in wind power.

Third, the methodology and assumptions for scaling up are selected to reflect the differences in circumstances. If the absolute methane intensity of Norwegian oil and gas production is unrealistic for other countries, they may still be able to replicate the relative rate of improvement over the past years.

Fourth, other countries are not expected to implement the solutions in the same way as in the originating Nordic country. Instead, each country can introduce a set of policies applicable in their specific circumstances - learning from the experiences of the Nordic countries and others.

While the Nordic countries have a lot to contribute, they also have a lot to learn from others. And while the countries have worked hard to limit their emissions, much more needs to be done in the coming years and decades.

\section{How realistic is the potential?}

Various factors affect how realistic the estimates on emission reduction potential are. In some respects the analysis may be overestimating and in some others underestimating the potential.

The potential may turn out to be smaller than identified in the study because scaling up solutions faces a number of barriers. To implement the solutions at scale, countries will need to overcome these barriers in very different and sometimes challenging circumstances.

On the other hand, the full potential may be larger due to a number of reasons. The solutions are only applied to the extent the Nordic countries have already achieved today. Some solutions have been defined fairly narrowly although there could be wider application. The scope of scale-up has been constrained both geographically and in terms of how far and fast other countries are expected to move. 
Furthermore, implementing a given solution in 2018-30 is likely to be quite different from doing it in, say, 2000-12. Technologies improve, prices drop, capacities are built, and experiences are gained. Also political and market support for climate action is likely to be stronger in the post-Paris world.

On balance, the analysis is likely to be conservative. In reality the potential to reduce emissions may be even larger than estimated in this report.

\section{In reality, the potential to reduce emissions may be even larger than estimated in this report.}

\section{Are the estimates reliable?}

There are several sources of uncertainties. In some cases, some of the data may outdated, inaccurate, aggregated or not available. Emissions may be affected by a complex web of factors, all of which cannot be taken into account in a project of this scope. Reduction potentials depend also on the extent to which the solution can be implemented, which, in turn can vary for a number of reasons.

To better reflect the uncertainties, a range is provided where feasible. Lower limits present a more pessimistic and upper limits a more optimistic estimate. A central value represents the best estimate within the parameters of this study. However, it may be helpful to focus on the broad messages and the orders of magnitude rather than the exact figures of each solution.

\section{Do the solutions overlap?}

In some cases, different solutions address the same emissions base. Where reasonable, we assume that solutions will be implemented in such a way as to minimise overlap.

The only solutions which overlap directly and unavoidably, are the ones that address energy use for heating: combined heat and power production (CHP), energy efficiency in buildings, residential heat pumps and bioenergy for heating. CHP, residential heat pumps and bioenergy for heating all reduce the carbon intensity of heating while the energy efficiency solution reduces the total demand for heating.
The four overlapping solutions only affect each other when they are implemented in the same regions. The total reduction in climate impact due to overlaps is $53 \mathrm{Mt}$ in 2025 and $137 \mathrm{Mt}$ in 2030. While this is by no means insignificant, it still represents only about $3 \%$ of the total emission reduction of the 15 solutions.

Some cases of indirect overlap can even increase the total potential for emission reductions. Solutions which reduce the carbon intensity of electricity generation (wind and geothermal power) increase the impact of solutions which require electricity (heat pumps and electric vehicles). The effect would be quite small, given that power sector solutions only reduce the total emissions of the sector by $772 \mathrm{Mt}$ in 2030, out of a total of almost $15 \mathrm{Gt}$ in the baseline scenario.

\section{How to go further?}

The analysed 15 solutions would cut global emissions by more than $4 \mathrm{Gt}$ annually. While this would be a significant improvement, even larger reductions are required to limit global warming to tolerable levels.

There are various ways to increase the impact of Nordic solutions. First, a larger number of solutions could be applied. The ones covered in this report represent only a fraction of all available and proven options.

Second, solutions could be extended to a larger number of countries, such as in the case of heat pumps. International support could enable developing countries to implement some of the solutions with higher costs.

Third, some of the solutions could be expanded to cover a larger share of emissions. For example, district heating could be coupled with district cooling and combined heat and power production applied in a larger number of industries.

Fourth, some countries may be able to go by 2030 beyond what Nordic countries have achieved today. While Norway has made good progress on electrifying the vehicle fleet, this is by no means the upper limit for other countries.

Fifth, factoring in future developments of technology would allow countries to do more. For example, newer wind technology with higher capacity factors can increase the amount of electricity that can be produced.

Finally, the emission potential would be larger if more recent data were available. Statistics may lag some years behind and since then the Nordic countries have moved further on many of the solutions. 


\section{Is biomass use sustainable?}

Three of the presented solutions rely on bioenergy: low-carbon energy in industry, biofuels in transport and bioenergy in heating. Large increases in biomass use tend to be controversial especially for two reasons.

First, energy production may divert biomass from other uses. Replacing pristine forests with monoculture plantations can threaten biodiversity. Growing crops for biofuel production can increase the demand for land and raise food prices, with potentially worrying impacts on food security for the poor. As part of an emerging circular economy, biomass may be better used first as material in products and only after that in energy use.

Second, biomass absorbs carbon dioxide from the atmosphere over time, but releases it instantaneously when burned. Even if bioenergy may be considered carbon-neutral in long timeframes of around 2050 and beyond, limiting global warming requires reducing emissions drastically already in the coming decades.

Low-carbon energy in industry and bioenergy for heating both use existing residues from the forestry industry and thus require no additional biomass extraction. The required bioenergy of approximately 3-4 exajoule (EJ) is relatively modest compared to estimated sustainable potentials. The Global Energy
Assessment by IIASA, for example, estimates the global potential for forestry residues to be 19-35 EJ per year.

Biofuels in transport require additional biomass extraction, and liquid biofuels are more likely to be made from crops grown on agricultural land. The needed 12-15 EJ of biofuel is 4-5 times greater than 2008 levels of bioenergy use for transport. However, there seems to be a relative consensus on the sustainable technical biomass potential being at least $100 \mathrm{EJ}$ per year.

There seems to be sufficient sustainable biomass available globally to fuel the analysed three bioenergy solutions. However, sustainability safeguards should be introduced to make sure that the use of bioenergy use does not lead to, for example, biodiversity loss.

Concerns about the true climate neutrality of biomass affect all bioenergy use. However, there is little consensus about how to assess net climate impacts of bioenergy. The results will depend sensitively on details of how and from where the biomass is sourced, which is beyond the scope of our analysis. For biofuels in transport, we apply an average emission factor taking into account the climate impact of their full lifecycle.

\section{There seems to be sufficient sustainable biomass available globally to fuel the analysed three bioenergy solutions. However, sustainability safeguards should be introduced.}




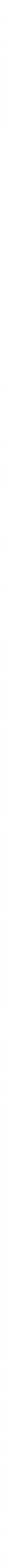




\section{Methodology}

\section{Selecting the solutions}

The 15 solutions were selected for analysis by the project steering group from a longer list of options mainly based on four criteria:

1. Nordic distinctiveness. The solutions have been pioneered by one or more Nordic countries or implemented to a notably large scale compared with other regions.

2. Proven impact. Each solution has a proven track record with a long enough history and significant enough scale in at least one Nordic country to assess the climate impact.

3. Analysis feasibility. Sufficient data is available from published and accessible sources. Estimating the potential is possible without a major modelling effort outside the scope of this project.

4. Scalability. Solutions can be implemented in several other countries.

Solutions with a large potential to reduce emissions were prioritised. However, also solutions with smaller potentials were included as many of them have other benefits.

The project also strived to maintain a reasonable geographical and sectoral balance. The 15 solutions are fairly evenly spread between the five Nordic countries and the five categories.

\section{Estimating the potential}

Analysing the climate impact of scaling up the solutions followed several steps. First, we selected a group of countries where it would be feasible to implement the solution. Second, we identified the degree to which the solution has been implemented in the originating Nordic country. We then scaled this up to the selected group of countries according to one of the following approaches:

1. Potential. Identify the share of the potential that has been achieved in the originating country. Then assume that target countries achieve the same level of implementation of their respective potentials by 2030 .

2. Change. Identify an appropriate measure of the growth rate of the solution in the originating country. Then assume that the target countries achieve that growth rate in 2018-30.
Third, we calculated the emission reductions. For example, for wind power we included estimating the emissions from replacing other power production using the average carbon intensity of electricity generation in the target countries. In the case of electric vehicles, we calculated the difference between emissions from petrol burnt in internal combustion engines and emissions from generating the electricity consumed by electric cars.

Finally, from this estimated abatement potential we subtracted the level of emission reductions expected to take place in a baseline scenario. The baseline broadly followed what countries would do if they were to implement their current policies, but would not introduce new targets or measures.

\section{Boundaries and constraints}

Various additional factors have to be considered when analysing and presenting the results. We explicitly adjusted for differences in carbon intensity of electricity generation in the originating country and the target countries. Where possible, we also used the projected carbon intensities of the target countries in 2025 and 2030 in the baseline scenario rather than the current values.

In some cases the methods may lead to an unrealistically or even impossibly high degree of implementation in some individual target countries. For example, wind power might reach a share of total electricity generation above what any electricity system could be expected to handle with current technologies. In these cases, we have applied a sanity check by defining upper limits beyond which none of the countries would go (for instance, onshore wind not reaching more than a $40 \%$ share of electricity production in any country).

The calculations cover emissions that are directly affected by the solution. We also included indirect emissions that are both significant and relatively straight-forward to define and quantify, such as emissions caused by changes in electricity consumption. We did not assess a wider carbon footprint, such as emissions from producing materials for new infrastructure. Such estimates would in most cases be complex, vary significantly with the local conditions and have high uncertainty. 


\section{Figure 5: Schematic description of methodology}

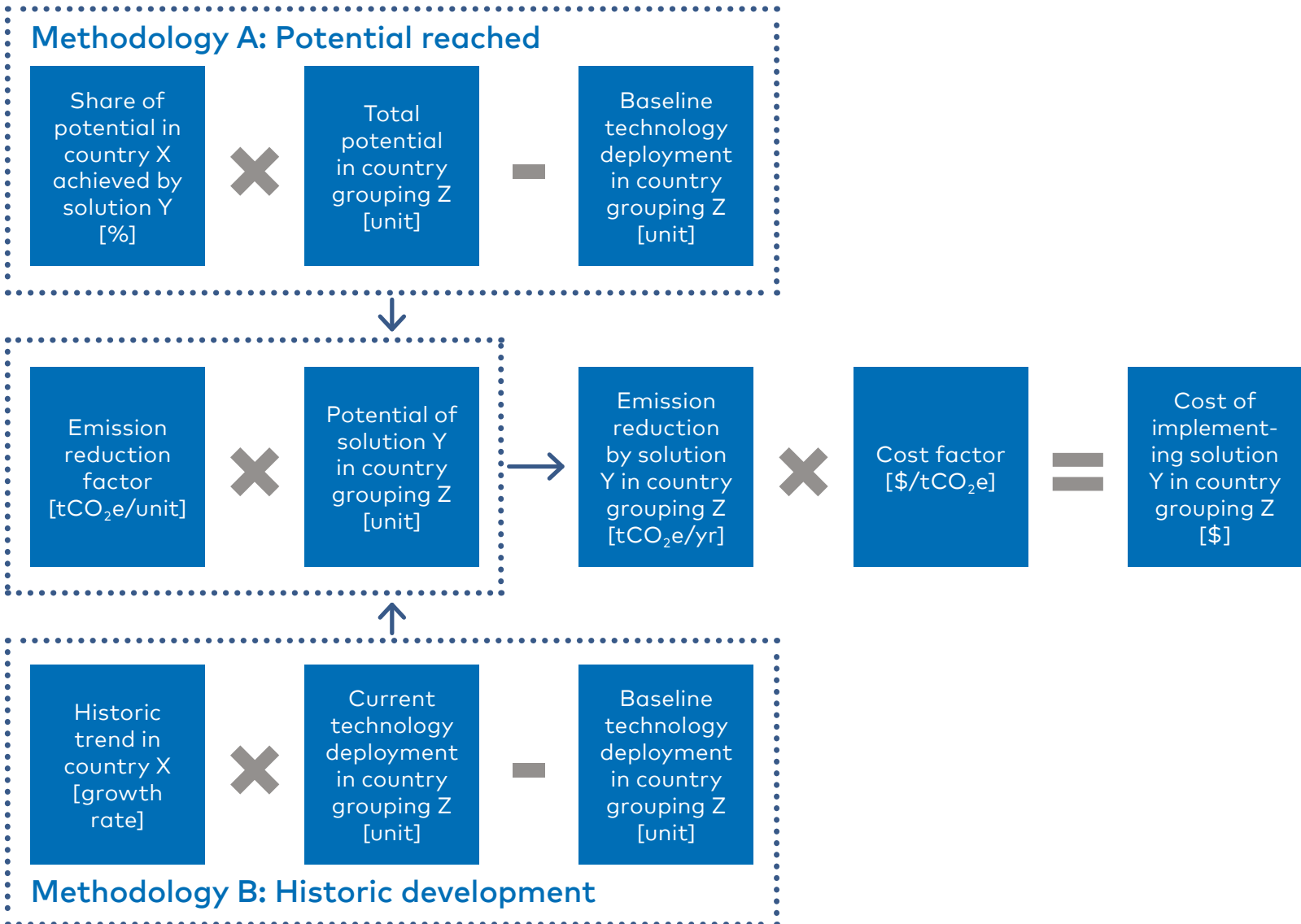

\section{Target countries}

Solutions were scaled up to countries with the necessary conditions and abilities to implement them. Factors defining scalability varied from one solution to another.

1. Economy. Solutions with relatively high abatement costs or expensive investments were scaled up only to economically developed countries.

2. Climate. Heating solutions were extended to countries with a large enough need for heating, and the Icelandic reforestation solution was only considered for countries with a temperate climate.

3. Natural resources. Bioenergy for heating was applied to countries with sufficient biomass resources, for example.

The scale up was also in some cases limited by considerations based on availability of data, projected level of achievement exceeding the Nordic solution's impact or size and magnitude of the activity (for instance, solutions related to oil and gas production were scaled up only to countries with a large net production). This reflects the general caution that was exercised in selecting the countries for scaling up the solutions to avoid overestimating the potential.

For some solutions there were no compelling reasons to limit the implementation. In those cases the solutions were scaled up globally.

\section{Costs}

We calculated the total cost of implementing each solution by first identifying a unit abatement cost in 2012 US dollars per tonne of $\mathrm{CO}_{2}$ e. We then multiplied that unit cost by the total abatement potential.

The primary source for unit abatement costs was version 2 of the Global Greenhouse Gas Abatement Cost Curve by McKinsey \& Company. Although somewhat old, the McKinsey cost curve is still the most comprehensive single consistent analysis available which is broad enough to cover many of the solutions we analysed.

To make sure that the cost levels in the McKinsey cost curve are still appropriate, we compared relevant data points in their documentation to more recent 
analyses. We also tried to adjust their cost figures to fit recent developments, in the cases where it was both necessary and possible.

Some solutions were not covered by the McKinsey cost curve, or McKinsey's analysis was clearly outdated. In these cases we either adapted estimates from other sources or constructed an independent estimate.

The cost estimates cover direct investment and operational costs, minus direct savings associated with implementing the solution. We have not quantified significant but hard-to-quantify elements such as savings from improved health or costs associated with longer commutes. Instead, we assessed the most important co-benefits qualitatively.

Abatement costs reflect the cost difference between the proposed solution and its conventional alternative. For example, the fact that scaling up onshore wind is expected to have a net cost implies that wind would, on average and taking into account integration costs, still be slightly more expensive than fossil alternatives in 2030. However, the estimate is highly sensitive to the relative cost of onshore wind and fossil power. Even minor improvement in favour of wind could turn the cost into a saving.

\section{Global warming potentials}

Most solutions reduce emissions of carbon dioxide $\left(\mathrm{CO}_{2}\right)$. Two of the solutions, however, reduce other greenhouse gases: methane $\left(\mathrm{CH}_{4}\right)$ in the case of reducing methane in oil and gas production, and nitrous oxide $\left(\mathrm{N}_{2} \mathrm{O}\right)$ in manure management.

We have converted the reductions in non- $\mathrm{CO}_{2}$ gases to $\mathrm{CO}_{2}$ equivalents $\left(\mathrm{CO}_{2} \mathrm{e}\right)$ by multiplying them by the global warming potentials (GWPs) established in the IPCC's 5th Assessment Report (AR5). Since different greenhouse gases have different lifetimes, the GWP for each gas differs depending on the timescales used.

We have used 100-year GWPs, as these are most commonly used in the literature. The mitigation potentials can easily be converted to a 20-year timescale by dividing the $\mathrm{CO}_{2}$-equivalent figures by the 100-year GWP and multiplying them by the 20year GWP.

If not specified otherwise, all emission numbers refer to $\mathrm{CO}_{2}$ e. The most commonly used units are megatonnes (millions of tonnes, $M t$ ) and gigatonnes (billions of tonnes, Gt).

\section{Suggested further reading}

More information on the methodology, assumptions, data and sources is available in the technical report. The report can be downloaded at www.greentoscale.net/nordic.

\section{The solutions were scaled up to countries with the necessary conditions and abilities to implement them.}




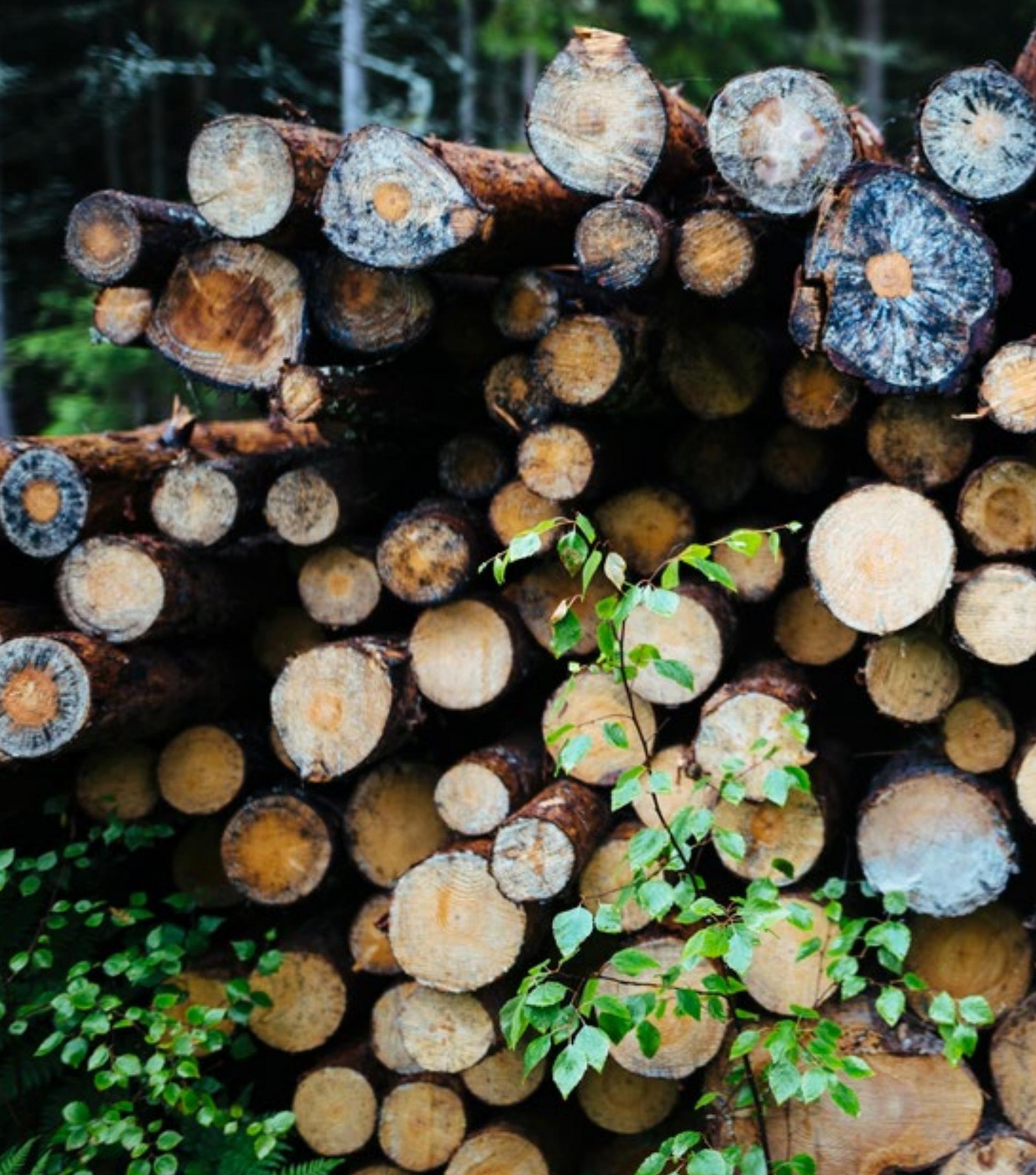

9) 18 


\section{Project Background}

THE NORDIC GREEN TO SCALE project was launched by the Finnish think-and-do tank Sitra (www.sitra. fi/en) in early 2016. Sitra served as the project secretariat. Core funding was kindly provided by the Nordic Council of Ministers Climate and Air Pollution Group KoL.

The analysis was commissioned to the Center for International Climate and Environmental Research - Oslo (CICERO, www.cicero.vio.no/en). At CICERO, the work was led by Senior Researcher Jan Ivar Korsbakken.

The project would have not been possible without the commitment and expertise of partners from three other Nordic countries: CONCITO from Denmark, the
Institute for Sustainability Studies at the University of Iceland and the Stockholm Environment Institute (SEI) from Sweden. In addition to these three institutions, also the Nordic Council of Ministers was represented on the project steering group.

Nordic Green to Scale builds on a similar project from 2015, with a global range of solutions. The final reports, other material and further information can be found at www.greentoscale.net.

If you want to know more, do not hesitate to contact the project secretariat (contact information at www.greentoscale.net/nordic). Please also let us know if you are interested in exploring possibilities for co-operation.

\section{The Nordic Green to Scale project was launched by the Finnish think-and-do tank Sitra in early 2016. It was developed in co-operation with renowned institutions from all five Nordic countries.}




\section{SOLUTIONS CATALOGUE}
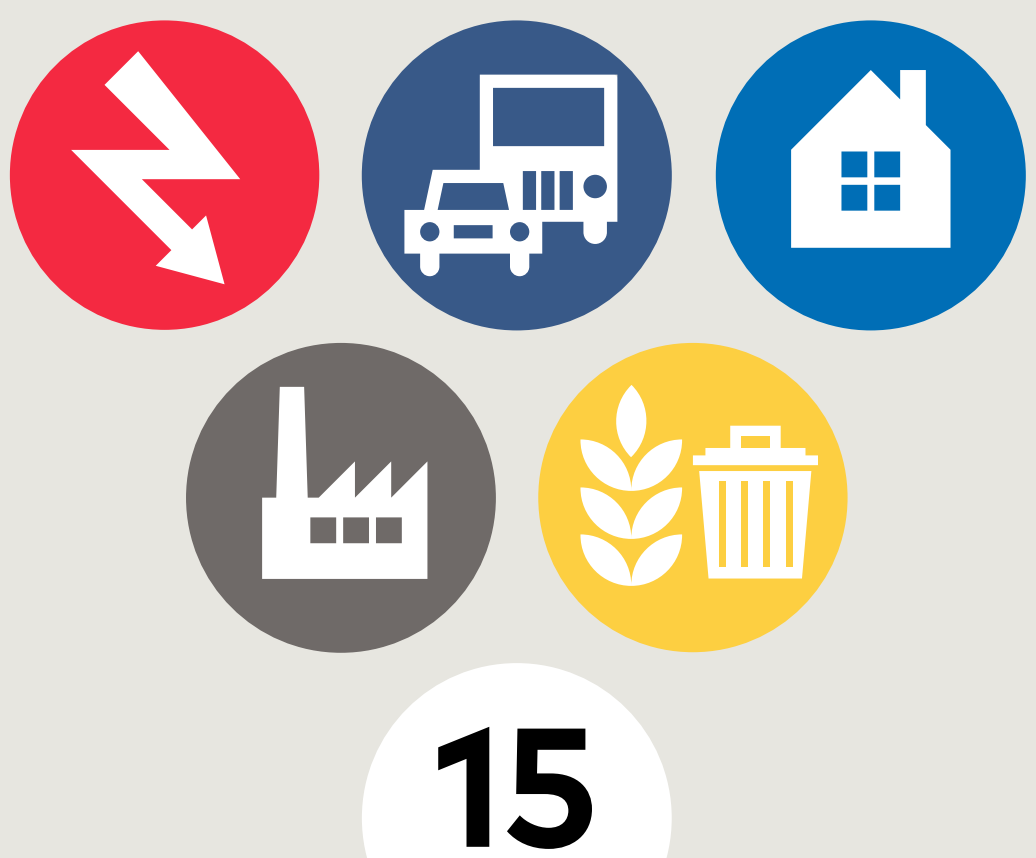

SOLUTIONS

\section{Nordic Green to Scale Low-carbon success stories}

We already have many tools available to cut emissions - as demonstrated by the results in the Nordic countries.

\section{We have solutions}

Scaling up just 15 Nordic climate solutions could cut global emissions annually by 4 gigatonnes in 2030 . This is equal to the current total emissions of the European Union.

\section{Nordic partnership}

Organisations from all five Nordic countries have partnered with the Finnish Innovation Fund Sitra and the Nordic Council of Ministers. The Nordic Green to Scale project has uncovered proven and attractive solutions to tackle the climate crisis.

\section{Countries can do more}

The results of this project show how implementing existing low-carbon solutions can take us a long way in tackling the climate crisis. Countries around the world have a range of proven and attractive Nordic solutions to choose from.

Read the full technical analysis and results at www.greentoscale.net/nordic. 


\section{Contents}

Combined heat and power production

Carbon capture and storage in oil

and gas production

Reducing methane in oil and gas production

Electric vehicles 


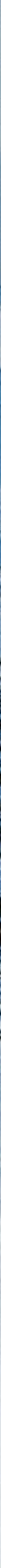




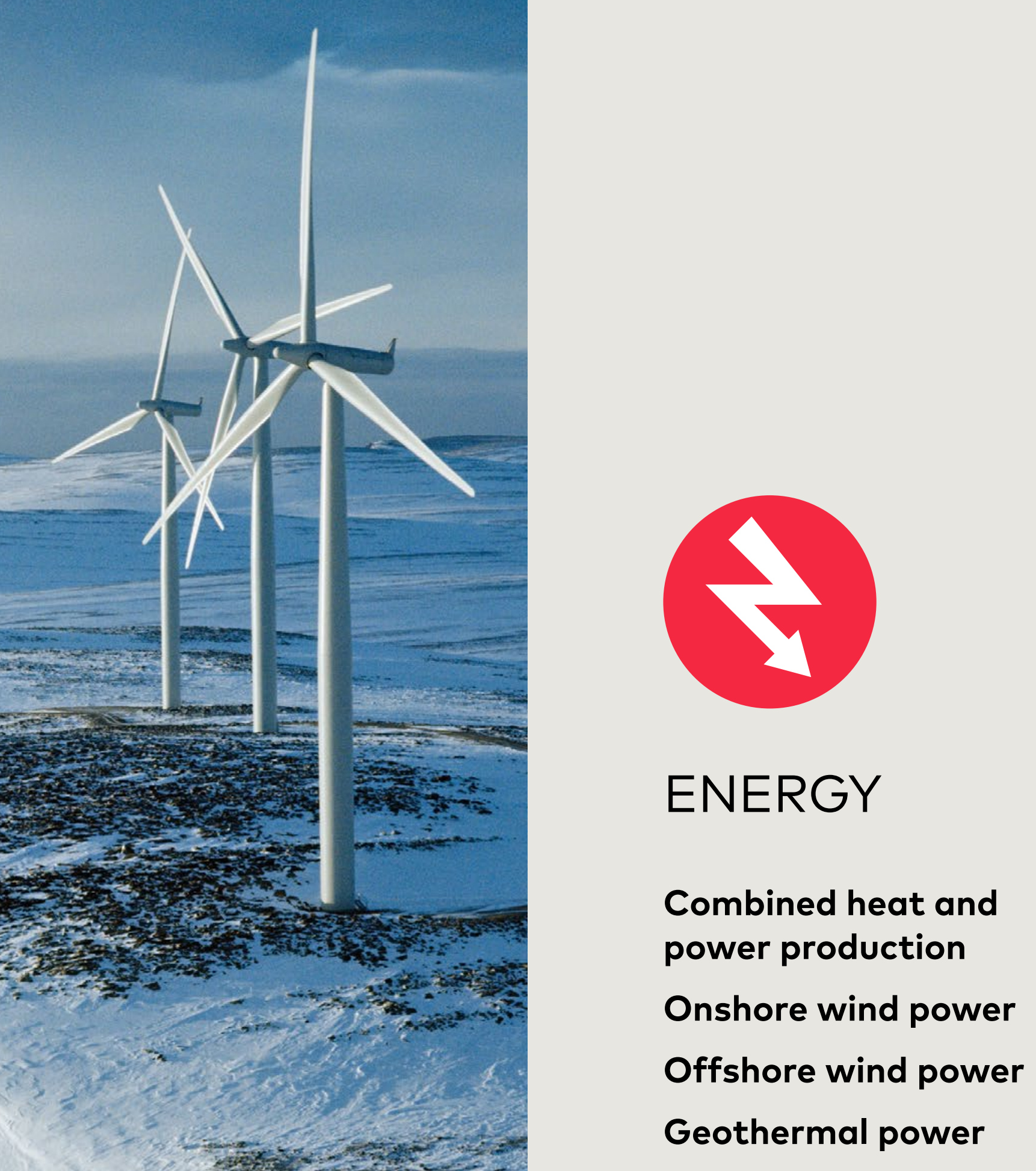




\title{
ENERGY
}

\section{Combined heat and power production}

\author{
Finland and Denmark have achieved high shares of \\ combined heat and power production. Scaling up the \\ solution both in industry and buildings could cut emissions \\ by almost as much as Japan produces every year.
}

\section{Climate impact}

Energy efficient combined heat and power (CHP) production covers almost $80 \%$ of industrial heat in Finland - a much higher share than in other countries. In Denmark and Finland most buildings in urban areas are covered with district heating and about 70-80\% of this heat is produced with CHP.

In the case of industrial heat, we have analysed the potential of scaling up Finnish shares of CHP globally in four industries: pulp and paper, chemicals, food and wood products. This would result in emissions savings of $292 \mathrm{Mt}$ in 2030.

In the case of buildings, we have applied the Danish and Finnish shares of district heating with CHP to urban areas in OECD countries, many of which have cold or temperate climates. Scaling up the solution would cut emissions by as much as $879 \mathrm{Mt}$ in 2030.

\begin{tabular}{|l|c|c|}
\hline Sector & 2025 & 2030 \\
\hline $\begin{array}{l}\text { Industry total } \\
\text { Paper and pulp }\end{array}$ & 179 & 292 \\
Chemical & 58 & 95 \\
Food & 112 & 182 \\
Wood products & 2 & 13 \\
\hline District heating & 563 & 3 \\
total (range) & $(477-649)$ & 879 \\
\hline CHP total & $\mathbf{7 4 2}$ & $\mathbf{7 4 6 - 1 , 0 1 1 )}$ \\
\hline
\end{tabular}

Figures in $\mathrm{MtCO}_{2}$ e. Totals may differ from the sum of the parts due to rounding.

\section{Success factors}

Key enablers for CHP and district heating are the incentives for the necessary infrastructure. Building a district heating network is much cheaper, if developers work together with urban planners to coordinate the construction of heating networks, CHP plants and buildings.

Finland has supported CHP production with fuel tax exemptions. Local governments have the authority to require buildings to join a district heating network.

Also in Denmark the local government can mandate connecting households to district heating. A support scheme subsidises the installation cost when swapping from other energy sources (oil and natural gas).

\section{Costs}

A weighted average cost for both retrofits and newbuilds in industrial CHP is $-6.6 \$ / \mathrm{tCO}_{2}$, thanks to fuel savings. Scaling up the solution would have a total negative cost of $\$ 1.9$ billion in 2030 .

Retrofitting existing buildings so that the full cost of the CHP and district heating system applies is very expensive at around $260 \$ / \mathrm{tCO}_{2}$ in 2030 . Taking also into account the lower cost when building CHP and district heating at the same time as a new building is constructed or an old one is refurbished, the lower construction cost combined with savings from lower fuel consumption results in a net saving of $-7 \$ / \mathrm{tCO}_{2}$ in 2030 .

This would result in estimated total net costs for both industrial and district heating CHP of - $\$ 8$ billion in 2030. Cost estimates have a large range, however, depending on assumptions about the rate of new construction and replacements, for example. 


\title{
ENERGY
}

\section{Onshore wind power}

\author{
Denmark has achieved the world's highest share of \\ wind in electricity production and Sweden a very high \\ growth rate. Scaling up this solution would cut global \\ emissions by more than Australia produces annually, \\ while cutting air pollution and creating local jobs.
}

\section{Climate impact}

In 2014, Sweden produced 11 TWh and Denmark 9.3 TWh of power with onshore wind. This covers $8 \%$ and $25 \%$ of the domestic electricity demand, respectively. Sweden has built $2 \%$ and Denmark $11 \%$ of their estimated technical onshore wind potential.

If other countries were to reach the same share of their technical onshore potential as Sweden and Denmark have on an average, they would produce 2,400 TWh more wind power in 2030 - assuming that the share of onshore wind in each country was capped at $40 \%$ of power production. This would cut global emissions by $695 \mathrm{Mt}$ in 2030.

\section{Success factors}

Denmark has been an early mover and invested in wind power already in the 1980s. The country has currently the world's highest share of wind power at over $40 \%$ of total generation, $60 \%$ of which is onshore.

Denmark has used a range of policies to promote wind power, including feed-in tariffs and renewable energy auctions. The country has set ambitious targets for low-carbon electricity, thus giving a clear signal to investors. Denmark aims to derive half of its electricity from wind by 2020 . By 2035 , all power and heat should come from renewable sources.

Sweden has had a consistently high growth in wind power over the past decade, with growth rates above $30 \%$ in most years. Wind turbines have largely been built with the support of green certificates, which require power companies to produce a growing share of electricity with renewable sources. Certificates can be traded on the market, creating a financial incentive to invest in wind power.

\section{Costs}

The abatement cost is estimated at $24 \$ / \mathrm{tCO}_{2}$. The cost is actually somewhat lower in 2025 than in 2030, since wind will later reach a higher penetration, increasing the integration costs.

The abatement cost reflects the price of replacing high-carbon electricity with wind power. As such it is sensitive not only to the costs of wind power, but also of the alternatives, such as coal. A relatively small hike in coal prices or drop in wind project costs can significantly cut the costs of scaling up.

\begin{tabular}{|l|c|c|}
\hline Abatement cost & 2025 & 2030 \\
\hline Unit abatement cost $\left(\$ / \mathrm{tCO}_{2}\right)$ & 24 & 24 \\
\hline Total (billion \$) & 14 & 17 \\
\hline
\end{tabular}

\section{Co-benefits}

Wind power provides multiple co-benefits, including

- cutting harmful air pollution

- reducing reliance on fuel imports

- improving trade balance

- creating local jobs 



\title{
ENERGY
}

\section{Offshore wind power}

\author{
Denmark already covers $14 \%$ of domestic electricity \\ demand with offshore wind power. Scaling up this \\ solution would cut global emissions by almost as \\ much as Panama produces annually, while cutting \\ fuel imports and improving energy security.
}

\section{Climate impact}

In 2014, Denmark produced 5.2 TWh electricity with offshore wind. This covers $14 \%$ of the domestic demand and represents $5 \%$ of the technical offshore potential in the country.

If other countries in OECD Europe, North America, Oceania and Asia were to reach the same level of their technical potential by 2030 , this would increase offshore wind production by 64 TWh in 2025 and 72 TWh in 2030. This, in turn, would cut emissions $22 \mathrm{Mt}$ in 2025 and 2030 . The figure is relatively low as countries are expected to build fairly large amounts of offshore wind already in the baseline scenario.

\section{Success factors}

Denmark has been an early mover on offshore wind. The country currently produces more than $40 \%$ of its electricity from wind power, of which $2 / 5$ comes from offshore wind. The offshore share is also growing.

To promote offshore wind, the Danish government has auctioned large-scale offshore wind parks with a price ceiling conducive for private sector engagement. Separately the government has guaranteed financing for grid connections from offshore wind parks.

Although more expensive than onshore wind, offshore wind has two major advantages. First, wind speeds offshore are higher and less variable than onshore, which leads to more electricity produced and a lower need for balancing power. Second, placing wind parks offshore reduces the demand for economically valuable land onshore as well as opposition due to noise or visual impacts.

\section{Costs}

The abatement cost is estimated to be $37 \$ / \mathrm{tCO}_{2}$ in 2030. In total, scaling up the solution would cost $\$ 840$ million in 2030.

\begin{tabular}{|l|c|c|}
\hline Abatement cost & 2025 & 2030 \\
\hline Unit abatement cost $\left(\$ / \mathrm{tCO}_{2}\right)$ & 40 & 37 \\
\hline Total (million \$) & 890 & 840 \\
\hline
\end{tabular}

\section{Co-benefits}

The co-benefits of offshore wind are largely the same as for onshore wind (see page 34), although it may require importing more technology and personnel.

Offshore wind can

- cut harmful air pollution

- reduce reliance on fuel imports

- improve energy security 


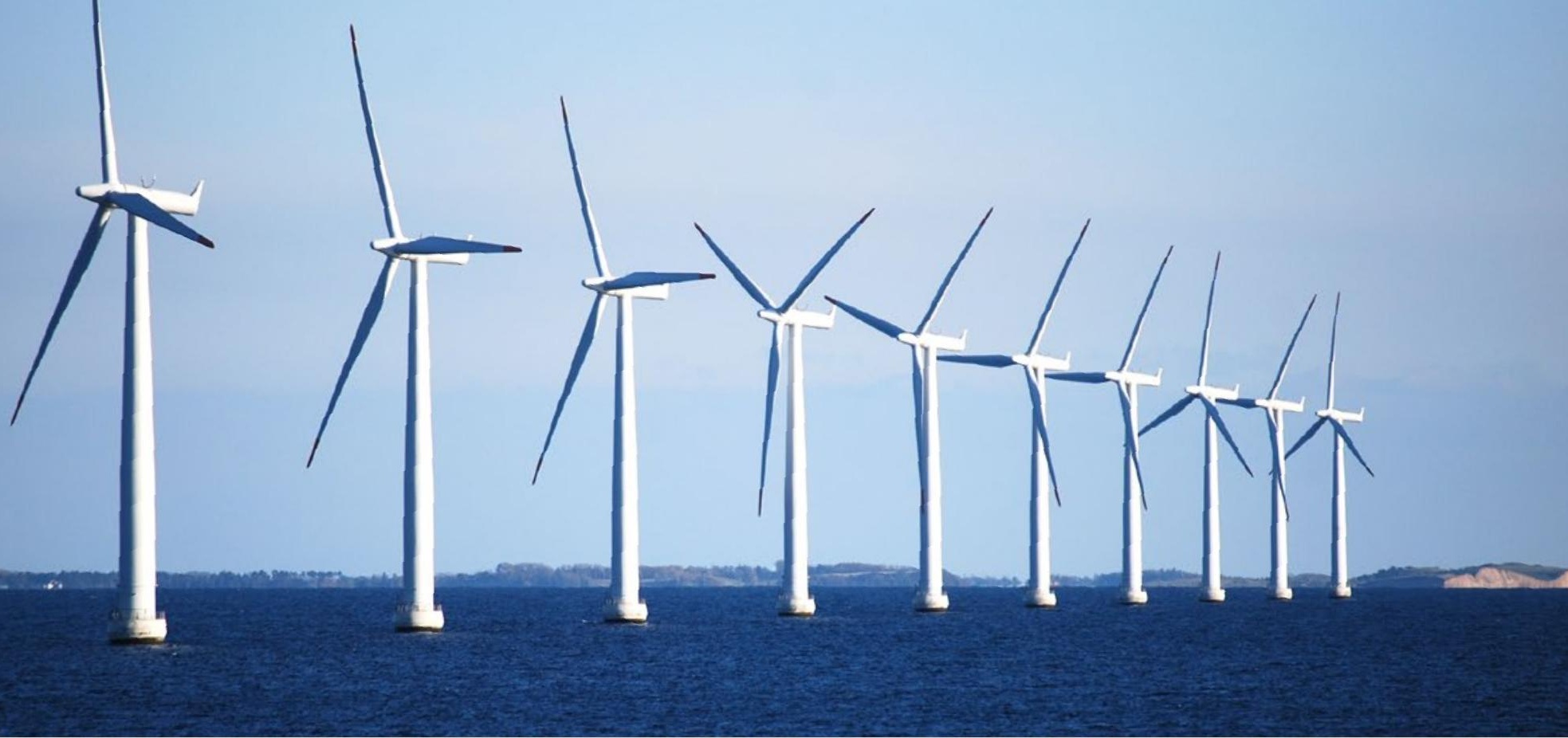

\section{Barriers and drivers}

Offshore wind faces many of the same barriers and drivers as onshore wind (see page 34). Compared with onshore, offshore has been significantly more expensive, thus requiring public support. However, costs have recently plummeted with the cheapest offshore project in Denmark selling electricity at less than $60 € / M W h$.

Wind speeds are generally more stable offshore reducing the barriers related to balancing the production. On the other hand, connecting offshore wind parks to the grid and operating the parks can be more challenging and costly than for onshore.

\section{Offshore wind provides more stable power production with less noise and visual impacts than onshore wind.}
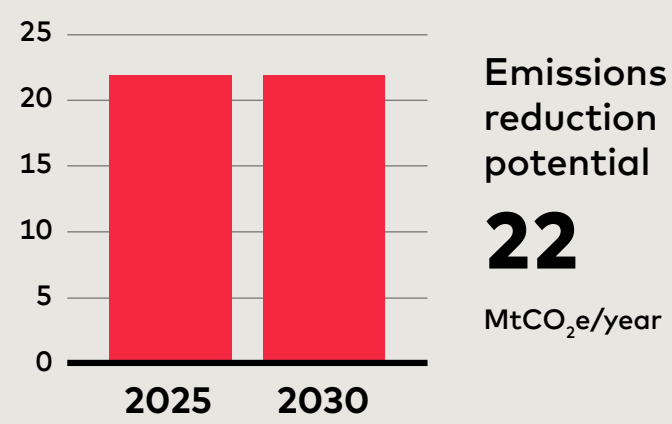

$\mathrm{MtCO}_{2} \mathrm{e} /$ year

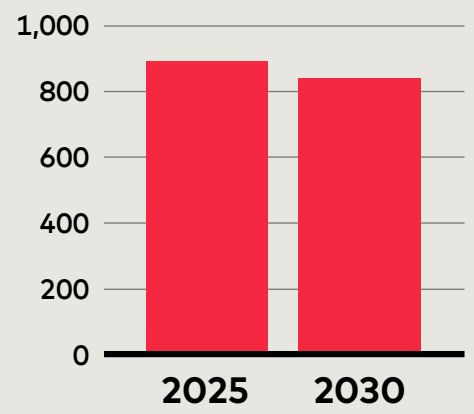

Total abatement costs 840 million \$ 


\title{
ENERGY
}

\section{Geothermal power}

\author{
Iceland is a world leader in harnessing geothermal \\ energy. Scaling up the solution to other countries \\ with significant potential would cut global emissions \\ by more than Denmark produces every year, \\ while reducing fuel imports.
}

\section{Climate impact}

Geothermal energy provides $29 \%$ of electricity and most of the heat in Iceland. While the production of heat has remained relatively stable over the past decades, power production has grown by $11 \%$ a year in 2001-13.

If other countries with significant geothermal potential were to achieve the same growth rate, the global production of geothermal power would increase by 60 TWh in 2025 and 150 TWh in 2030. After including the $\mathrm{CO}_{2}$ emissions from geothermal power this would result in a net emission reduction of $55 \mathrm{Mt}$ in 2030.

\begin{tabular}{|l|ccc|ccc|} 
& \multicolumn{3}{|c|}{2025} & \multicolumn{3}{c|}{2030} \\
& Lower & Central & Upper & Lower & Central & Upper \\
\hline $\begin{array}{l}\text { Reduction } \\
\text { potential } \\
\text { MtCO }_{2} \mathrm{e}\end{array}$ & 20 & $\mathbf{2 4}$ & 27 & 46 & 55 & 64 \\
\hline
\end{tabular}

\section{Success factors}

Geothermal energy provides a stable source of power. It can therefore act as a good baseload complement to variable renewables. The technology also requires less land area than practically any other renewable energy source and in most cases does not have a significant impact on ecosystems.

Iceland has an exceptionally high geothermal potential relative to the size of its population. In 2013, Iceland produced $7.3 \%$ of geothermal electricity and a remarkable $75 \%$ of geothermal delivered heat in the world.

Iceland has traditionally met most of its electricity needs through hydropower, but during the 2000s has expanded geothermal power generation on a large scale. Geothermal electricity generation in 2013 was 5.3 TWh, while it is estimated that 10-30 TWh could be generated sustainably with current technology. Government initiatives include low-cost and guaranteed loans for exploratory drilling, as well as funding of demonstration projects and research.

\section{Costs}

The abatement cost is estimated at $5.5 \$ / \mathrm{tCO}_{2}$ in 2030. The total abatement costs are $\$ 304$ million in 2030.

\begin{tabular}{|l|ccc|ccc|} 
& \multicolumn{3}{|c|}{2025} & \multicolumn{3}{c|}{2030} \\
& Lower & Central & Upper & Lower & Central & Upper \\
\hline $\begin{array}{l}\text { Total } \\
\text { costs } \\
\text { million \$ }\end{array}$ & 154 & 182 & 210 & 253 & 304 & 355 \\
\hline
\end{tabular}




\section{Co-benefits}

Geothermal power provides several co-benefits, such as

- cutting harmful air pollution

- reducing fuel imports

- improving energy security

\section{Barriers and drivers}

Geothermal power requires significant investments, but can provide a relatively stable power source for a long time. That is why it would benefit from predictable power-purchasing arrangements such as power purchasing agreements (PPAs).

If laws about ownership of underground resources are not clear or above-ground land owners have effective veto power, geothermal power plants can face legal obstacles. Reforming legislation to ease the use of geothermal resources can remove the biggest hurdles.

Geothermal power is economically most attractive in areas that are geologically active, such as Iceland, Indonesia and New Zealand. In other areas geothermal production would require drilling very deep wells, which would rely on experimental technology and increase costs.

\section{Geothermal power production requires very little land and has very few ecological impacts.}

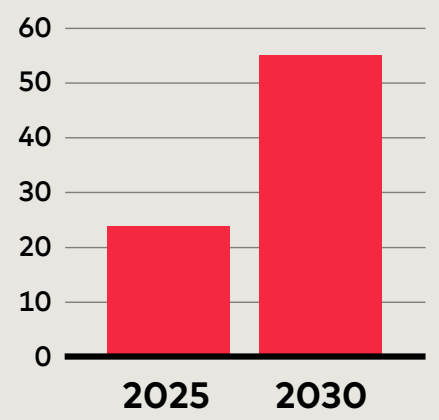

Emissions reduction potential

\section{5}

$\mathrm{MtCO}_{2} \mathrm{e} /$ year

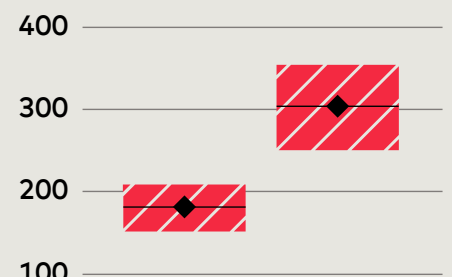

Total abatement costs 304

million \$ 


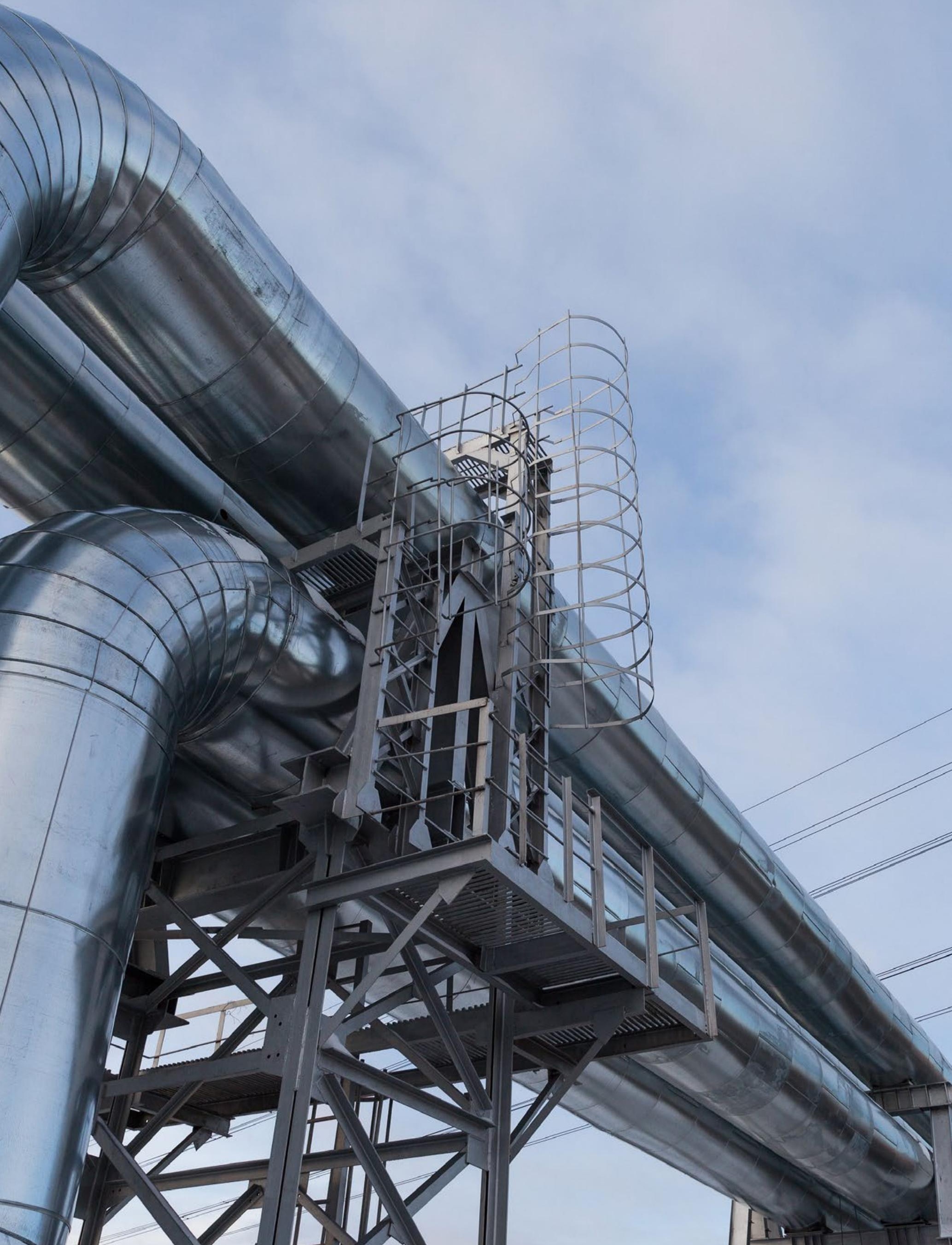



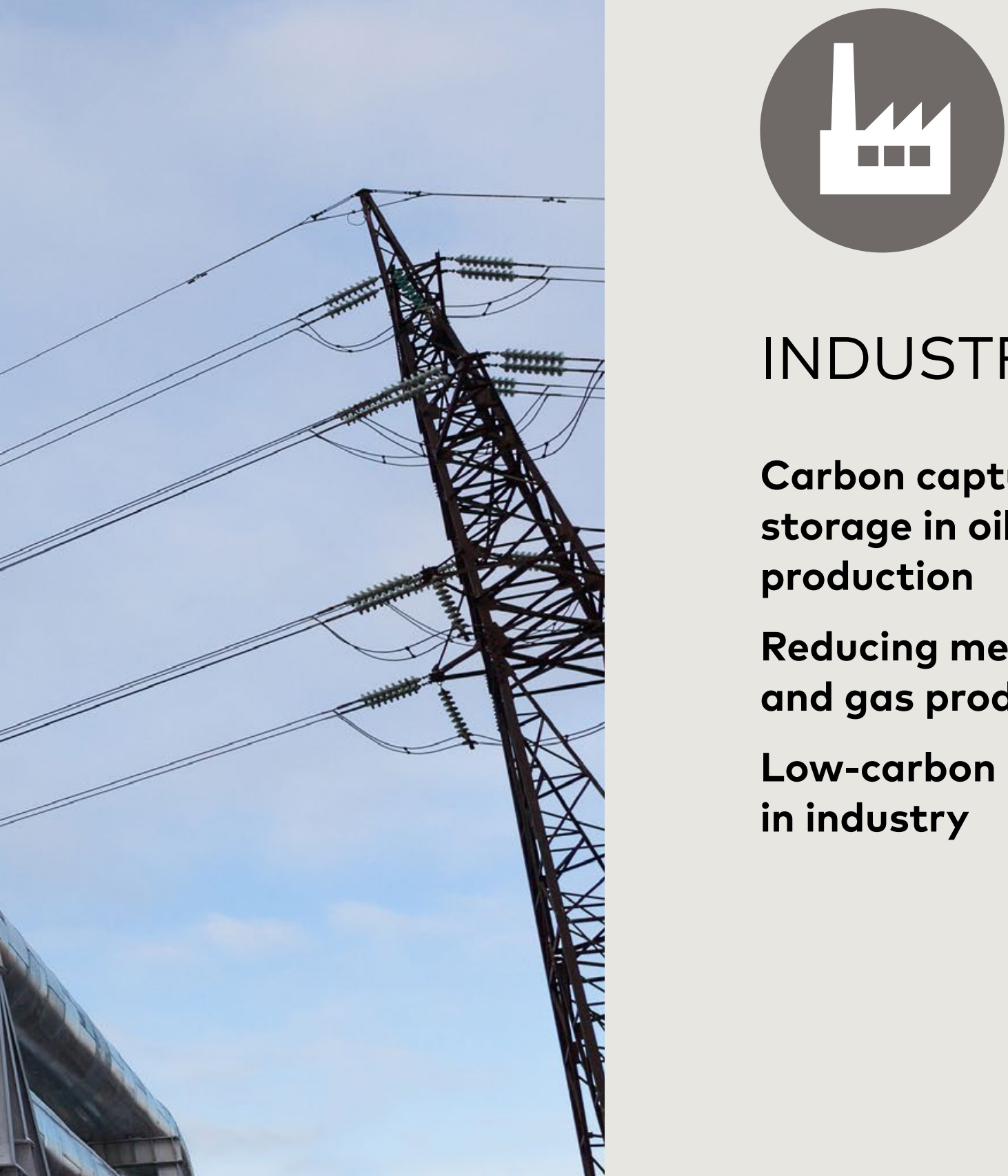

INDUSTRY

Carbon capture and storage in oil and gas production

Reducing methane in oil and gas production

Low-carbon energy in industry 


\title{
Carbon capture and storage in oil and gas production
}

\author{
Norway has been the first to capture geological carbon dioxide from oil \\ and gas production at large scale and store it permanently. Scaling up \\ the solution to other countries producing oil and gas would reduce global \\ emissions by as much as Hungary produces every year.
}

\section{Climate impact}

Since the start of operations, the carbon capture and storage (CCS) installations at Sleipner and Snøhvit fields in Norway have captured approximately $19 \mathrm{Mt}$ of the geological $\mathrm{CO}_{2}$ that is extracted from oil and gas reservoirs and normally vented to the atmosphere. This represents $90 \%$ of all vented $\mathrm{CO}_{2}$ from oil and gas production in Norway.

The technology used is relatively simple and affordable as it involves a fairly pure stream of $\mathrm{CO}_{2}$ which has already been separated as part of normal natural gas processing. We have therefore applied the solution to relatively wealthy gas- and oil-producing countries with significant emissions in OECD and the Middle East as well as China, India, Indonesia, Malaysia, Brunei and Argentina.

The emission reduction potential depends on which types of oil and gas production and which categories of emissions are included. If other countries were to reach the Norwegian share of capturing the relevant $\mathrm{CO}_{2}$ by 2030 , this would reduce global emissions on an average by $63 \mathrm{Mt}$ in 2030.

\begin{tabular}{|l|ccc|ccc|} 
& \multicolumn{3}{|c|}{2025} & \multicolumn{4}{c|}{2030} \\
& Lower & Central & Upper & Lower & Central Upper \\
\hline $\begin{array}{l}\text { Reduction } \\
\text { potential } \\
\mathrm{MtCO}_{2} \mathrm{e}\end{array}$ & 5 & 36 & 79 & 11 & 63 & 137 \\
\hline
\end{tabular}

\section{Success factors}

Oil and natural gas reservoirs can contain significant amounts of geological $\mathrm{CO}_{2}$, which is often released to the atmosphere either through leakages or venting.
CCS captures the $\mathrm{CO}_{2}$ and stores it permanently, usually in a geological reservoir.

Statoil operates two oil and natural gas fields which sequester fugitive $\mathrm{CO}_{2}$ from natural gas extraction. Sleipner began capturing $\mathrm{CO}_{2}$ at an offshore facility in the North Sea in 1996 and Snøhvit at an onshore processing site in the Barents Sea in 2008. The $\mathrm{CO}_{2}$ is injected into sedimentary rocks approximately 1,000 metres below the sea floor.

Both projects have been motivated by an emission tax introduced in 1991. The tax was approximately $35 \$ / \mathrm{tCO}_{2}$ in 1996 at the time operations began at Sleipner and has since been raised to the current level of $65 \$ / \mathrm{tCO}_{2}$. Another driver has been meeting a European cap of $2.5 \%$ on the $\mathrm{CO}_{2}$ content of natural gas. The Norwegian government also required CCS as a precondition for Snøhvit receiving a license to operate.

\section{Costs}

Capturing geological $\mathrm{CO}_{2}$ from oil and gas production is cheaper than applications where emissions are captured from power plants. Based on the costs for the Sleipner project, we have adopted an estimate of $33 \$ / \mathrm{tCO}_{2}$ as the central value. This results in total costs of $\$ 2.1$ billion in 2030 .

\begin{tabular}{|l|ccc|ccc|} 
& \multicolumn{3}{|c|}{2025} & \multicolumn{4}{c|}{2030} \\
& Lower Central & Upper & Lower & Central Upper \\
\hline $\begin{array}{l}\text { Abatement } \\
\text { costs } \\
\$ / \mathrm{tCO}\end{array}$ & 17 & 33 & 48 & 17 & 33 & 48 \\
\hline $\begin{array}{l}\text { Total } \\
\text { costs } \\
\text { billion } \$\end{array}$ & 0.09 & 1.2 & 3.8 & 0.18 & 2.1 & 6.6 \\
\hline
\end{tabular}




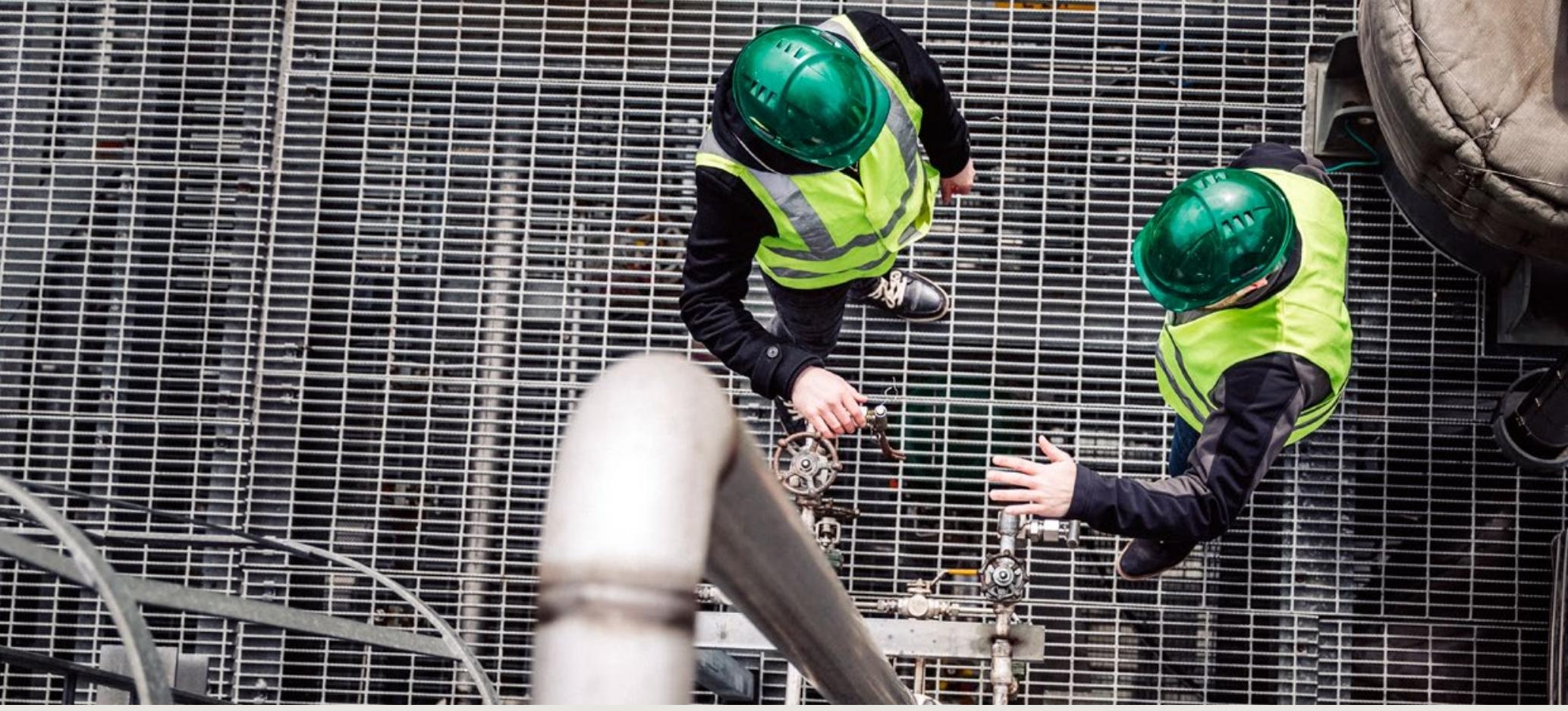

\section{Co-benefits}

Carbon capture and storage is motivated by climate benefits alone. The solution does not provide any significant co-benefits.

\section{Barriers and drivers}

Public resistance towards CCS is a significant obstacle. Fears about leakage and safety, general NIMBYism and concerns that CCS provides an excuse for continuing to use fossil fuels have contributed to CCS being unpopular. Attitudes may change as people become aware of the role CCS may play in limiting warming to well below two degrees. However, more information needs to be provided.

Geological $\mathrm{CO}_{2}$ storage requires specific types of sedimentary rocks, which limits the potential in some areas. It is not a major concern for upstream oil and gas production, since oil and gas fields are usually associated with the type of formations needed. Overall the new method developed in Iceland to inject $\mathrm{CO}_{2}$ into basaltic rocks shows great promise.

The most important enabler for CCS is to establish a financial incentive. CCS has little commercial value beyond reducing climate risks. As a result, government incentives or mandates are needed.

Some regions have a poorly developed legal framework and requirements for safety and longterm monitoring of stored $\mathrm{CO}_{2}$. Ensuring consistent regulations would help improve predictability for investors and thus expedite investment decisions once the financial incentives are in place.

\section{Norway has been capturing carbon emissions in oil and gas production since 1996.}

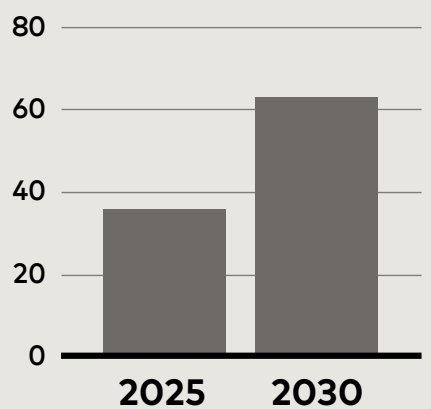

Emissions reduction potential

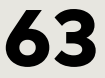

$\mathrm{MtCO}_{2} \mathrm{e} /$ year

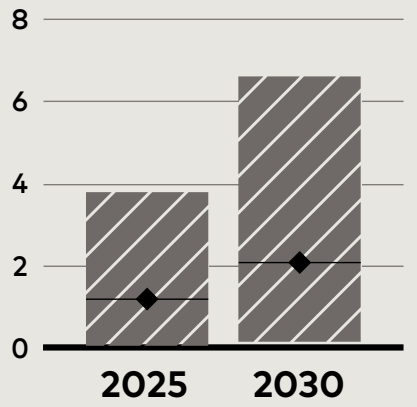

Total abatement costs 2.1 billion \$ 


\title{
Reducing methane in oil and gas production
}

\author{
Norway has achieved the world's lowest methane emission intensity \\ in oil and gas production. Scaling up the solution to other oil- and gas- \\ producing countries would cut global emissions by almost as much as \\ Ukraine produces every year, while improving employee safety and health.
}

\section{Climate impact}

Between 2000 and 2010, Norwegian oil and gas production has reduced its methane emission intensity by $2.3 \%$ per year on an average. According to official statistics the level is only $2.8 \mathrm{kgCH}_{4} / \mathrm{TJ}$ which is exceptionally low by international standards.

Other relatively developed and significant oiland gas-producing countries without considerable programmes to cut upstream emissions can probably achieve the same annual reduction in methane intensity. Replicating the Norwegian improvement would cut global emissions by $357 \mathrm{MtCO}_{2} \mathrm{e}$ in 2030.

\begin{tabular}{|l|lll|lll|} 
& \multicolumn{3}{|c|}{2025} & \multicolumn{3}{c|}{2030} \\
& Lower & Central & Upper & Lower & Central & Upper \\
\hline $\begin{array}{l}\text { Reduction } \\
\text { potential } \\
\text { MtCO }_{2} \mathrm{e}\end{array}$ & 200 & 216 & 233 & 329 & 357 & 384 \\
\hline
\end{tabular}

\section{Success factors}

Methane $\left(\mathrm{CH}_{4}\right)$ is the main component of natural gas. It is also a potent greenhouse gas, with a global warming potential 30-36 times that of carbon dioxide over a 100-year period.

Methane is released both intentionally and unintentionally as part of oil and gas extraction, as so-called fugitive emissions. Most intentionally released methane is burnt on release (flaring) in case the production site is too far away from a major demand centre to make selling the gas attractive.
Norwegian oil and gas production is reported to have the lowest methane intensity of any major oil- or gas-producing country. The country has also seen a steady decline in methane intensity over the past decade greater than the global average rate of improvement.

According to the industry itself, success is not primarily the result of a focus on reducing methane leakages, but rather due to strict safety regulations and high-quality equipment. All oil and gas production in Norway also takes place offshore, which requires greater attention to pipe sealing and equipment durability than onshore production.

\section{Costs}

We have estimated the solution to cost approximately -15 $\$ / \mathrm{tCO}_{2}$ in 2030 as the reclaimed methane can be sold to the market. The total savings would then be $-\$ 5.1$ billion in 2030 .

\begin{tabular}{|l|ccc|ccc|} 
& \multicolumn{3}{|c|}{2025} & \multicolumn{3}{c|}{2030} \\
& Lower Central & Upper & Lower & Central & Upper \\
\hline $\begin{array}{l}\text { Abatement } \\
\text { costs } \\
\$ / \mathrm{tCO}_{2} \mathrm{e}\end{array}$ & -27 & -17 & -7 & -24 & -15 & -7 \\
\hline $\begin{array}{l}\text { Total } \\
\text { costs } \\
\text { billion } \$\end{array}$ & -5.3 & -3.3 & -1.4 & -8.0 & -5.1 & -2.1 \\
\hline
\end{tabular}




\title{
Low-carbon energy in industry
}

\author{
Pulp and paper industry in Finland and Sweden has reached \\ very low levels of carbon intensity. Scaling up the solution to \\ other countries would cut emissions by more than Singapore \\ produces every year, while reducing fuel imports.
}

\section{Climate impact}

Finland and Sweden have some of the world's highest shares of bioenergy in pulp and paper industry. This is one of the main reasons why the industry in Finland has had a carbon intensity of $14 \mathrm{tCO}_{2} / \mathrm{TJ}$ and Sweden just $4 \mathrm{tCO}_{2} / \mathrm{TJ}$, compared with the global average of $35 \mathrm{tCO}_{2} / \mathrm{TJ}$. The low carbon intensities have saved $0.7 \mathrm{MtCO}_{2}$ in Finland and $2.1 \mathrm{MtCO}_{2}$ in Sweden per year relative to the $O E C D$ average.

For countries both inside and outside of OECD, we have considered reaching Finland's annual reduction rate in carbon intensity. Additionally, for OECD countries we have looked at achieving Finland's average absolute carbon intensity.

The more moderate approach would reduce emissions by $20 \%$ below OECD average, whereas the more ambitious one would result in cutting emissions by $30 \%$. The total emission reduction potential would be $57 \mathrm{Mt}$ in 2030 .

\begin{tabular}{|l|ccc|ccc|} 
& \multicolumn{3}{|c|}{2025} & \multicolumn{4}{c|}{2030} \\
& Lower & Central & Upper & Lower & Central & Upper \\
\hline OECD & 6 & 9 & 12 & 11 & 16 & 21 \\
\hline $\begin{array}{l}\text { Non- } \\
\text { OECD }\end{array}$ & & 24 & & & 41 & \\
\hline Total & 31 & 34 & 37 & 52 & 57 & 63 \\
\hline
\end{tabular}

Figures in $\mathrm{MtCO}_{2} \mathrm{e}$.

\section{Success factors}

The pulp and paper industry in Nordic industries has achieved a low carbon intensity expressed in $\mathrm{CO}_{2}$ emissions per energy used. Typically the levels have been less than two-thirds of the OECD average and one-third to one-half of the world average.

The pulp and paper industry derives a high share of energy from biomass by using waste and residues from their main raw material, wood. Over the period 2003-13, the industry in Finland and Sweden got $76 \%$ and $89 \%$ of its non-electricity final energy consumption from bioenergy, respectively. By comparison, the OECD average for 2013 was only $54 \%$ and the global average $39 \%$.

The industry started to move away from oil after the oil crises. Factories also reduced pollution by burning residues rather than releasing them into nearby waterways. In Sweden green certificates reward electricity from renewables, making it profitable to invest in electricity generation based on by-products such as black liquor and forestry residues.

\section{Costs}

The costs can vary greatly depending on local circumstances. We have derived a cost estimate from replacing coal with biomass in the chemical industry with both new build and retrofits as the closest analogue. In reality, the costs may be a good deal smaller since more of the biomass used in the pulp and paper industry will come from industry byproducts and waste.

The abatement cost has been estimated at $23 \$ / \mathrm{tCO}_{2^{\prime}}$ leading to a total cost of $\$ 1,310$ million in 2030 . 


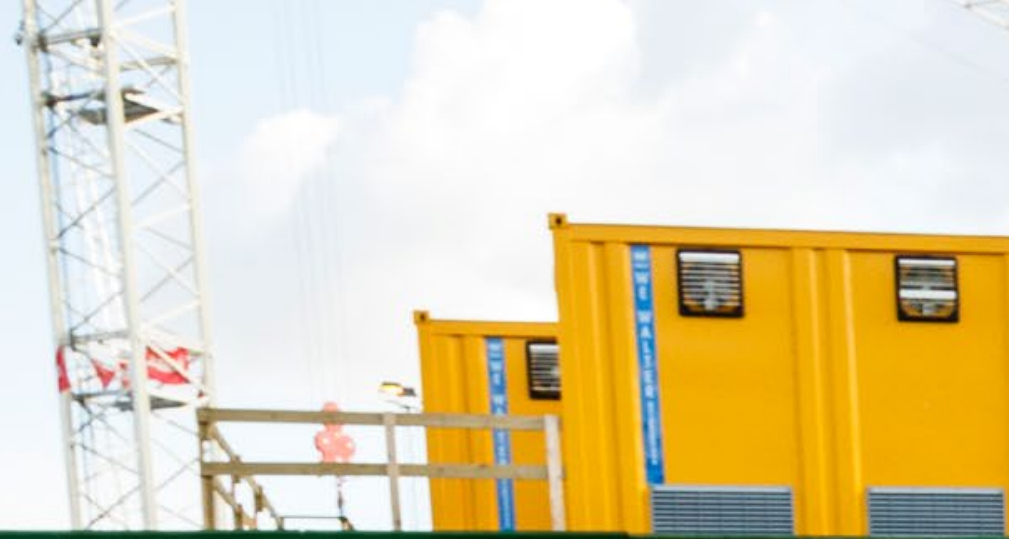

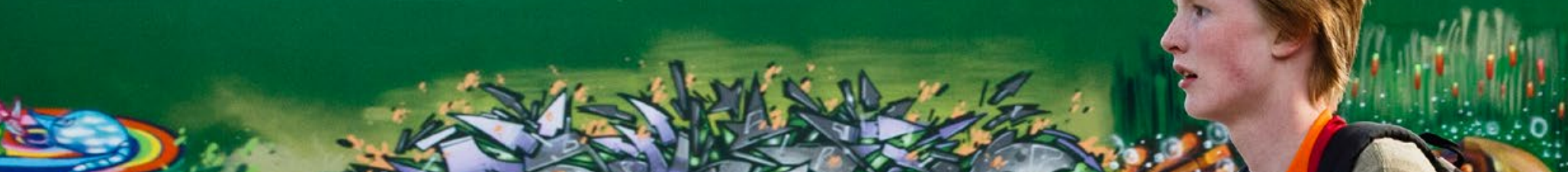

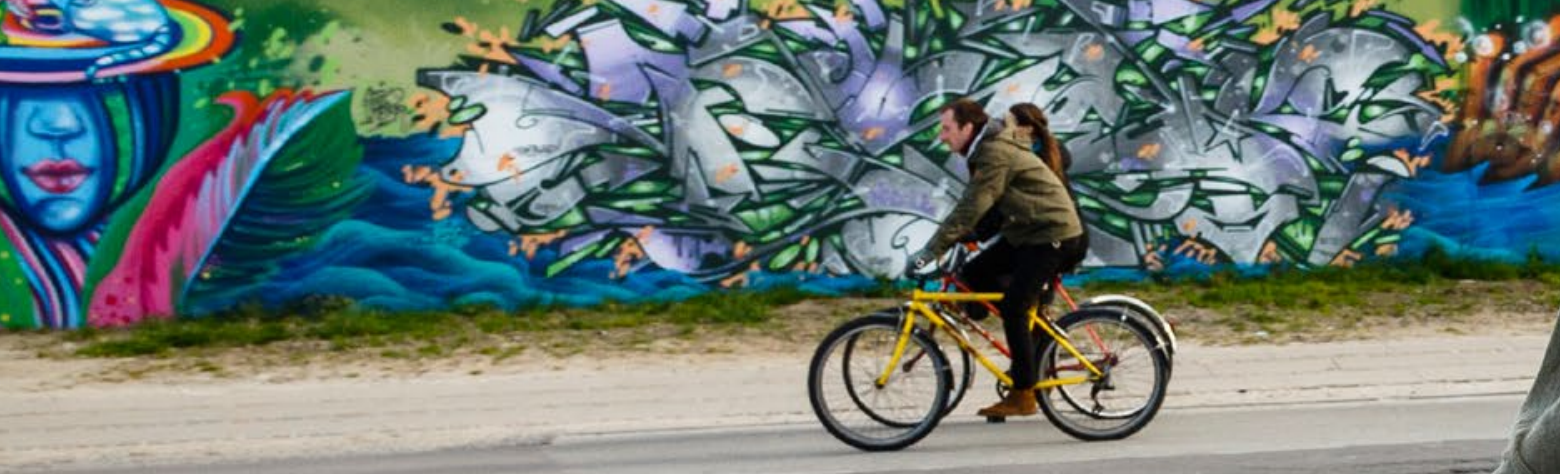




\title{
Electric vehicles
}

\author{
Norway has the highest share of electric vehicles in \\ the world. If other wealthy countries were to follow \\ the example, this would reduce global emissions by \\ nearly as much as Denmark produces every year, \\ while cutting harmful air pollution and noise.
}

\section{Climate impact}

Danes living in urban areas cycle $2.8 \mathrm{~km}$ per day Norway is a world leader in replacing conventional cars with EVs. At the end of 2015, $2.6 \%$ of private cars in Norway were electric vehicles (EVs) and $0.5 \%$ plug-in hybrid vehicles (PHEVs). In 2015, 17\% of newly registered cars were EVs and 5.3\% PHEVs.

We have considered two cases in which OECD countries, Brazil and China emulate the Norwegian achievement. In the first case, other countries achieve Norway's 2015 share of vehicles in their car fleet by 2030. The second case is based on other countries achieving and retaining Norway's 2015 share of vehicles in new sales from 2018 to 2030.

The global abatement potential in 2030 is approximately $50 \mathrm{Mt}$. The emission reduction is relatively small as countries are expected to increase the share of EVs significantly already in the baseline scenario.

\begin{tabular}{|l|ccc|ccc|} 
& \multicolumn{3}{|c|}{2025} & \multicolumn{4}{c|}{2030} \\
& Lower & Central & Upper & Lower & Central & Upper \\
\hline $\begin{array}{l}\text { Based on } \\
\text { Norway's } \\
\text { fleet }\end{array}$ & 7 & 8 & 9 & 17 & 20 & 23 \\
\hline $\begin{array}{l}\text { Based on } \\
\text { Norway's } \\
\text { sales }\end{array}$ & 70 & 77 & 84 & 69 & 76 & 83 \\
\hline Overall & 7 & 46 & 84 & 17 & 50 & 83 \\
\hline
\end{tabular}

Figures in $\mathrm{MtCO}_{2}$ e. The overall figures present the full range of the two scenarios with the central figure as the best estimate.

\section{Success factors}

In Norway, EVs are exempt from car registration taxes, value added tax (VAT), road tolls and parking fees in public spaces. The annual registration fee is heavily reduced and EVs may use public transport lanes. Charging stations have also been built in most urban areas, as well as between the largest cities.

In 2015, the vehicle tax based on $\mathrm{CO}_{2}$ emissions was reduced also for PHEVs. This has resulted in a large increase in the sale of PHEVs.

\section{Costs}

We estimate EVs and PHEVs to have abatement costs of 135 and $28 \$ / \mathrm{tCO}_{2}$, respectively. The figures do not include the capital costs of charging infrastructure.

\begin{tabular}{|l|ccc|ccc|}
\hline & \multicolumn{3}{|c|}{2025} & \multicolumn{3}{c|}{2030} \\
\hline & Lower & Central & Upper & Lower & Central & Upper \\
\hline $\begin{array}{l}\text { Based on } \\
\text { Norway's } \\
\text { fleet }\end{array}$ & 0.9 & $\mathbf{1 . 0}$ & 1.0 & 2.2 & $\mathbf{2 . 3}$ & 2.4 \\
\hline $\begin{array}{l}\text { Based on } \\
\text { Norway's } \\
\text { sales }\end{array}$ & 9.5 & $\mathbf{9 . 7}$ & 9.9 & 9.3 & $\mathbf{9 . 5}$ & 9.7 \\
\hline Overall & 0.9 & $\mathbf{5 . 4}$ & 9.9 & 2.2 & $\mathbf{6 . 0}$ & 9.7 \\
\hline
\end{tabular}

Figures in billion $\$$. The overall figures present the full range of the two scenarios with the central figure as the best estimate.

\section{Co-benefits}

EVs and, to a lesser extent, PHEVs provide multiple co-benefits, such as

- cutting harmful air pollution

- reducing fuel imports

- cutting fuel bills

- reducing noise 


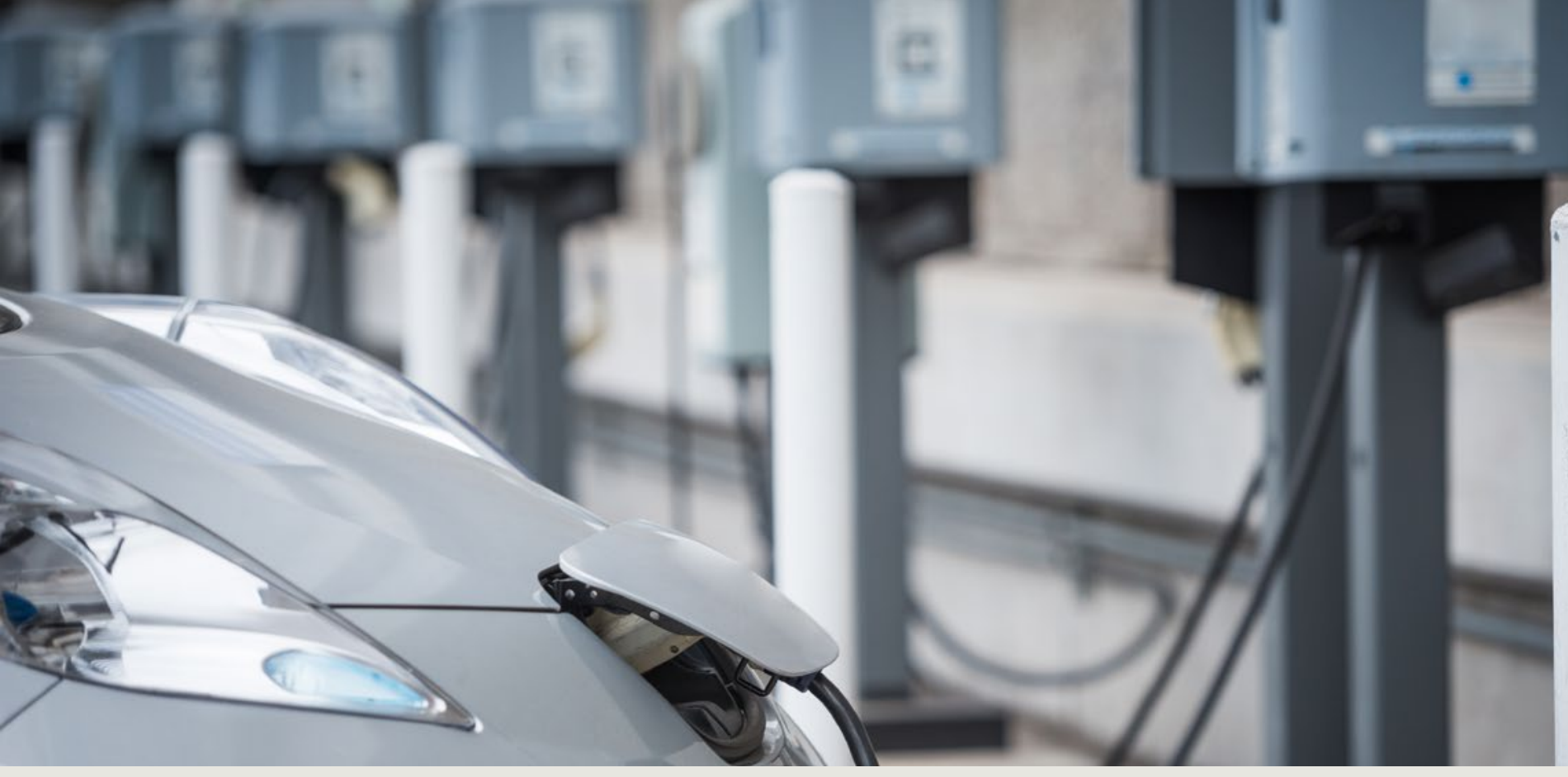

\section{Barriers and drivers}

EVs in Norway are essentially zero-emission cars as the electricity mix in Norway contains almost no fossil fuels. However, EVs cut emissions also in many countries with high shares of coal power. We also see a general trend towards decarbonisation of power production.

EVs are more economical in markets where electricity is relatively cheap and gas and diesel relatively expensive, such as the Nordic countries. In countries where this is not the case, additional measures may be required, such as removing subsidies on fossil fuels.

As most Nordic countries have high taxes for cars, tax exemptions provide a significant incentive. Countries with lower taxes would need to apply other incentives. For instance, in Germany, car buyers receive $\$ 4,500$ when they choose an electric vehicle, with the cost shared $50-50$ between public funds and car manufacturers.

Both buying new EVs and building the necessary charging infrastructure entail relatively high capital costs. Although some of the costs will be offset by reductions in fuel use and increasing co-benefits, at current prices $E V s$ are affordable mostly in wealthier countries. New and more affordable models as well as domestic manufacturers in countries like India may change the picture, however.

\section{More than 1/5 of new cars sold in Norway are already electric or plug-in vehicles.}

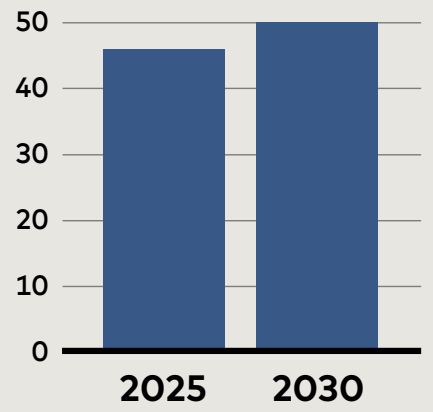

Emissions reduction potential

50 $\mathrm{MtCO}_{2} \mathrm{e} /$ year

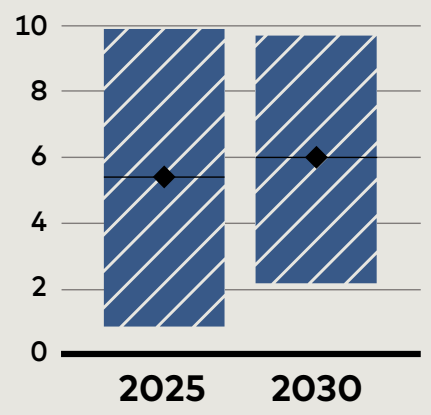

Total abatement costs 6.0 billion \$ 


\title{
Biofuels in transport
}

\author{
Sweden and Finland cover around $10 \%$ of their \\ transport needs with biofuels. Scaling up this solution \\ globally could reduce emissions by almost as much as \\ Italy produces every year, while creating local jobs.
}

\section{Climate impact}

Sweden and Finland cover $11.9 \%$ and $9.3 \%$ of their transport energy use with biofuels, respectively. As most of the fuels are used in road transport, the share there is higher. Both countries rely predominantly on biodiesel, but Sweden also uses some bioethanol and biogas.

If other countries were to reach the same share of biofuels in transport as Sweden, the net abatement potential would be approximately $510 \mathrm{Mt}$ in 2030. The Finnish case gives a smaller potential. The figures assume that biofuels reduce emissions by $60 \%$ on an average compared with fossil fuels.

\begin{tabular}{|l|ccc|ccc|} 
& \multicolumn{3}{|c|}{$\begin{array}{l}2025 \\
\text { Lower }\end{array}$} & \multicolumn{4}{c|}{2030} \\
\hline $\begin{array}{l}\text { Swedtral } \\
\text { share }\end{array}$ & 118 & 236 & 354 & 253 & 506 & 760 \\
\hline $\begin{array}{l}\text { Finnish } \\
\text { share }\end{array}$ & 82 & 164 & 246 & 170 & 340 & 511 \\
\hline Combined & 100 & 200 & 300 & 212 & 423 & 635 \\
\hline
\end{tabular}

Figures in $\mathrm{MtCO}_{2} \mathrm{e}$.

\section{Success factors}

Sweden and Finland have reached relatively high shares of biofuels in road transport. The primary policy has been a blending obligation: regulation requiring fuel companies to provide a growing share of biofuels in the fuels they distribute.

In Finland, taxation is based on the energy content and carbon emissions of fuels. As no emission taxes are levied on biofuels, this provides an added incentive.
In Sweden, local governments have been the driving force behind the introduction of biogas. Local authorities have provided both feedstock from organic waste and sewage as well as demand by requiring the use of biogas in public vehicles, such as buses and garbage trucks.

\section{Costs}

A weighted average of biofuels gives an abatement cost of $1.9 \$ / \mathrm{tCO}_{2}$. First generation biofuels have a slightly negative abatement cost per ton, while second generation biofuels have a slightly larger, but positive abatement cost. The total cost of implementing the solution would then be approximately $\$ 800$ million in 2030 .

\begin{tabular}{|l|ccc|ccc|} 
& \multicolumn{2}{|c|}{2025} & \multicolumn{3}{|c|}{2030} \\
& Lower & Central & Upper & Lower & Central Upper \\
\hline $\begin{array}{l}\text { Total } \\
\text { costs } \\
\text { million \$ }\end{array}$ & 188 & 376 & 564 & 398 & 796 & 1,194 \\
\hline
\end{tabular}

\section{Co-benefits}

While there is a variety of different biofuels and feedstocks, some of them can provide multiple cobenefits, such as

- reducing dependence on fuel imports

- cutting local air pollution

- creating local jobs 


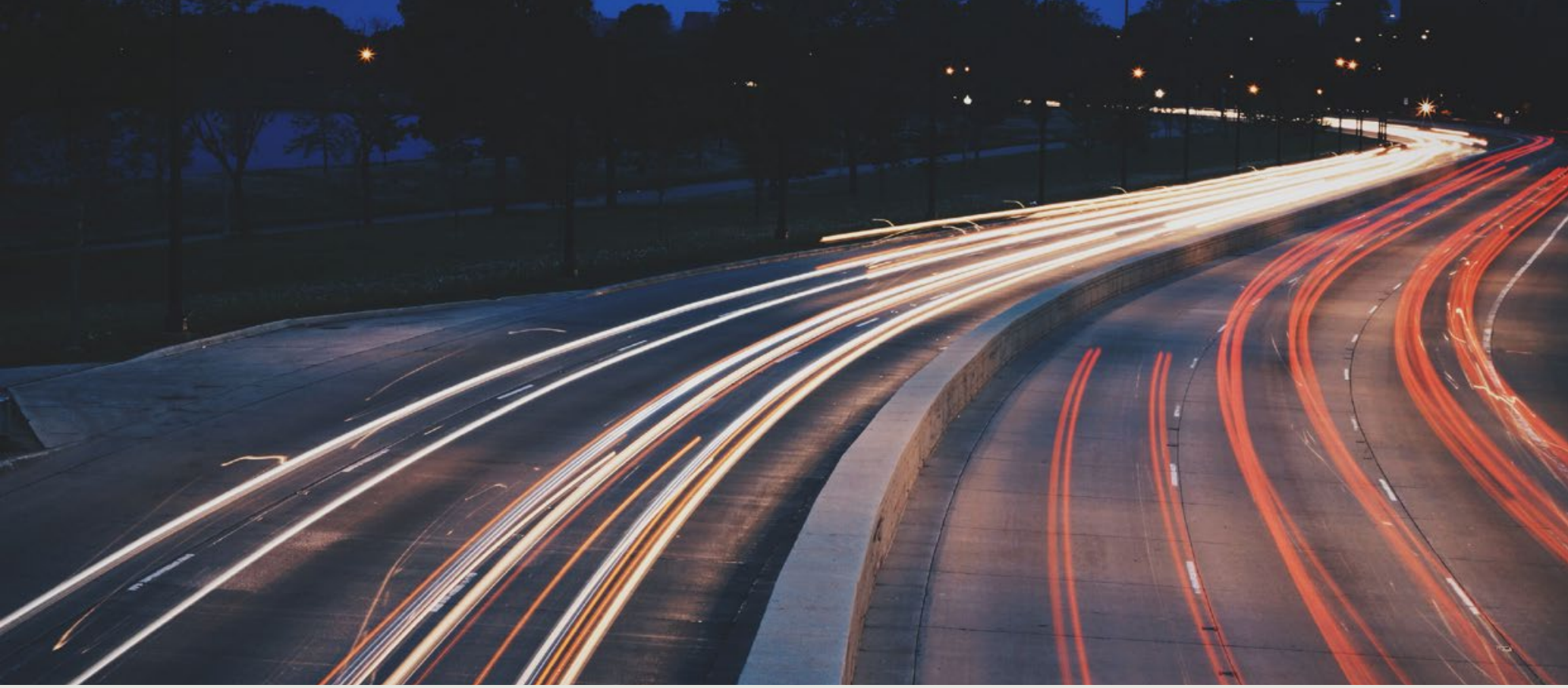

\section{Barriers and drivers}

One of the main barriers to the introduction of biofuels at scale is the concern about sustainability (see page 21). Different feedstocks have wildly varying impacts on climate, biodiversity and food security. Waste- and residue-based biofuels are generally more sustainable than first generation biofuels made from dedicated crops.

The availability of sustainable biomass is limited with current technologies. Improvements in technology (such as more efficient conversion processes), new feedstocks (such as algae and community-based crops grown on degraded lands) and regulation to limit harmful impacts (such as indirect land-use change, ILUC) are likely to increase the potential in the future.

Although enough sustainable biomass may be made available, limited resources may need to be prioritised. For the time being, there are very few low-carbon options available for aviation, shipping and heavy duty road transport. It may therefore make sense to electrify the car fleet (see page 50) and dedicate most of biofuels to heavy transport.

Existing gas and diesel cars can usually tolerate a $10-20 \%$ share of biofuels. To achieve higher shares, either new cars need to be introduced or drop-in biofuels selected, allowing the use in existing cars.

\section{Waste- and residue-based biofuels are generally more sustainable.}

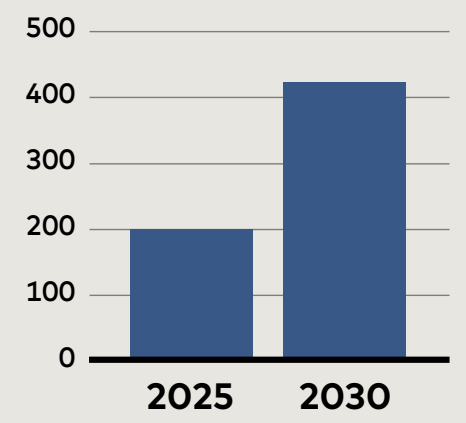

\section{Emissions reduction potential 423}

$\mathrm{MtCO}_{2} \mathrm{e} /$ year

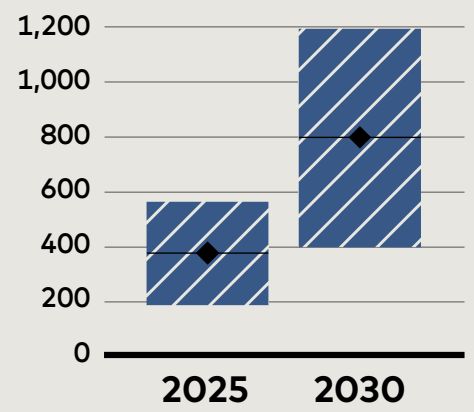

Total abatement costs 796 million \$ 


\section{Cycling in cities}

\section{People in Danish cities cycle more than almost anyone else in the world. Scaling up the solution to other urban areas would cut emissions by more than Slovakia produces every year while reducing congestion.}

\section{Climate impact}

Danes living in urban areas cycle $2.8 \mathrm{~km}$ per day on an average - one of the highest numbers in the world. Cycling replaces a mix of trips with car, public transport and walking.

As the Danish level is very high and circumstances in other areas may be more challenging, we assume that in other countries cycling can grow by a maximum of $30 \%$ by 2030 . With this constraint scaling up the solution to urban areas in other countries would reduce emissions by $23 \mathrm{Mt}$ in 2025 and $37 \mathrm{Mt}$ in 2030. We assume that cycling replaces mostly travel by bus and car and, to a lesser extent, walking.

\section{Success factors}

Denmark has one of the highest shares of cycling in the world. Reaching comparable levels requires a combination of behavioural change, infrastructure investment and determined policies to promote cycling.

In Denmark, policies have focused on urban planning, transportation policies that favour cycling and bike parking facilities. A national cycling strategy coupled with a DKK 1 billion support scheme for expanding the cycling infrastructure in municipalities and designated cycling towns has focused on connecting cycling with public transport systems, promoting cycling opportunities in relation to both the workplace and leisure purposes, and safe cycling for school children. The strategy has also enabled others to initiate procycling actions of their own, in particular municipalities and public transport authorities.

\section{Costs}

Estimating costs for cycling is difficult as the solution relies largely on behavioural change. Based on the costs from building and maintaining bicycle paths as well as reduced fuel costs, we estimate promoting cycling to have a negative cost of about $-0.02 \$ / \mathrm{km}$.

This would result in an estimated abatement cost of $-14 \$ / \mathrm{tCO}_{2}$ in 2025 and $-42 \$ / \mathrm{tCO}_{2}$ in 2030 . The net abatement cost would then be $-\$ 310$ million in 2025 and $-\$ 1,550$ million in 2030 .

\section{Co-benefits}

Cycling provides multiple significant co-benefits, including

- cutting harmful air pollution

- reducing congestion

- improving health

- cutting noise

- freeing up urban space for other uses 



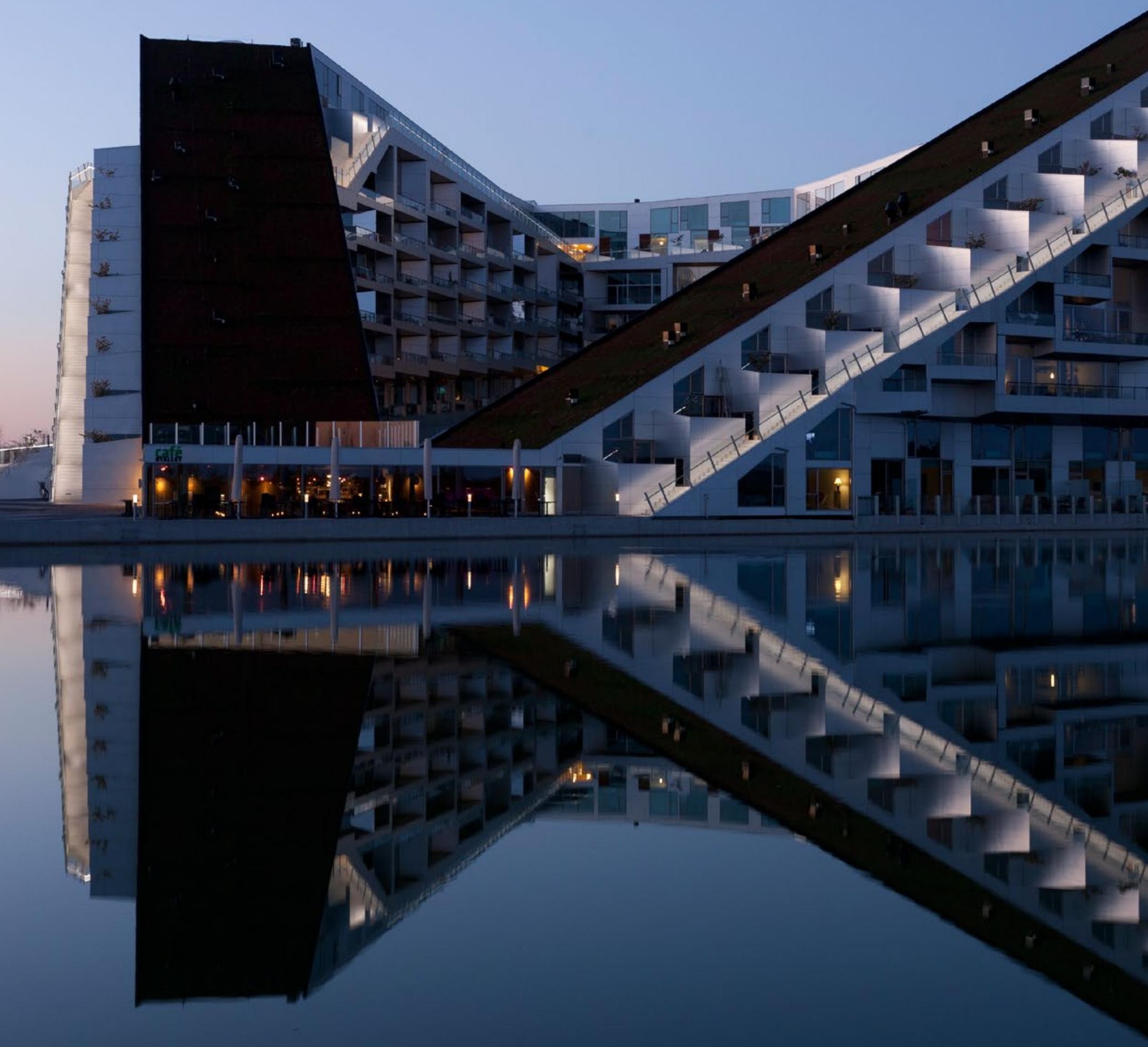




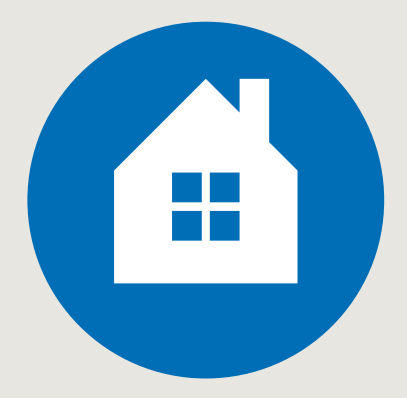

\section{BUILDINGS AND HOUSEHOLDS}

Energy efficiency in buildings

Residential heat pumps Bioenergy for heating 


\title{
\# BUILDINGS AND HOUSEHOLDS
}

\section{Energy efficiency in buildings}

\author{
Sweden has cut energy use in buildings faster than most \\ other countries. Scaling up the solution to comparable \\ regions would reduce emissions by more than Spain \\ produces every year while improving housing quality.
}

\section{Climate impact}

Sweden has been able to reduce energy use per area in buildings by $1.9 \%$ a year in 2002-13. Both heating and electricity use per square metre have declined in all main building types.

Similar progress can be expected from countries in comparable economic and climate conditions. If they were to achieve the same annual reduction in energy use per square metre as Sweden, this would cut emissions by $280 \mathrm{Mt}$ in 2025 and $340 \mathrm{Mt}$ in 2030.

\begin{tabular}{|l|c|c|}
\hline & 2025 & 2030 \\
\hline USA & 170 & 266 \\
\hline EU & 86 & 126 \\
\hline Japan & 23 & 38 \\
\hline Total & 280 & 430 \\
\hline
\end{tabular}

Figures in $\mathrm{MtCO}_{2} \mathrm{e}$.

\section{Success factors}

Average energy consumption per square metre has shown a downward trend in all Nordic countries in the last decade. However, Sweden is the only country where also the absolute energy consumption has declined, by close to $1 \%$ per year, despite the moderate growth in economy, population and building mass.

Nordic governments and industry have paid attention to improving energy efficiency in buildings. There has recently been a trend towards very lowor even net-zero energy buildings. Countries have also improved efficiency standards for lighting and appliances as part of the European internal market.
Sweden has organised technology procurement groups which cooperate on procuring efficiency technologies and exchange experiences. Some $20 \%$ of all commercial space and $70 \%$ of all apartment buildings are estimated to be covered by such groups. Efficiency requirements in the building codes have also been ramped up. Information about opportunities for efficiency improvements is actively distributed through municipal climate and energy advisors as well as the Swedish Energy Agency.

\section{Costs}

The relevant measures are quite diverse. That is why the unit costs range from more than $70 \$ / \mathrm{tCO}_{2}$ to savings of more than $-130 \$ / \mathrm{tCO}_{2}$. However, the most commonly used measures vary between approximately 0 and $-40 \$ / \mathrm{tCO}_{2}$. We apply this range to estimate the net abatement cost in both 2025 and 2030.

\begin{tabular}{|l|ccc|ccc|} 
& \multicolumn{3}{|c|}{2025} & \multicolumn{3}{c|}{2030} \\
& Lower & Central & Upper & Lower & Central & Upper \\
\hline $\begin{array}{l}\text { Total } \\
\text { costs } \\
\text { billion \$ }\end{array}$ & 0.0 & $-\mathbf{5 . 6}$ & -11.2 & 0.0 & $-\mathbf{8 . 6}$ & $-\mathbf{1 7 . 2}$ \\
\hline
\end{tabular}




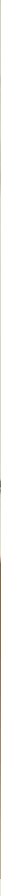

\section{Co-benefits}

Improving energy efficiency in buildings can provide several co-benefits, such as

- cutting harmful air pollution

- increasing housing quality

- improving energy security

\section{Barriers and drivers}

Energy efficiency improvements in buildings often produce net savings, but the payback time can be long. More importantly, the savings often accrue to tenants rather than those making decisions about investments (developers and landlords). Policy makers therefore need to put in place explicit requirements such as building codes and possibly also financial incentives such as tax credits.

In areas with low energy prices, there is only little incentive to care about energy efficiency measures. Raising taxes on energy use in buildings can increase the attractiveness of efficiency improvements.

Awareness of energy efficiency in buildings is often low. Therefore, information and awareness campaigns are important. Regulatory requirements will also signal that energy efficiency is a priority, helping to raise awareness.

\section{Sweden has cut energy use in buildings despite the growth in economy and population.}

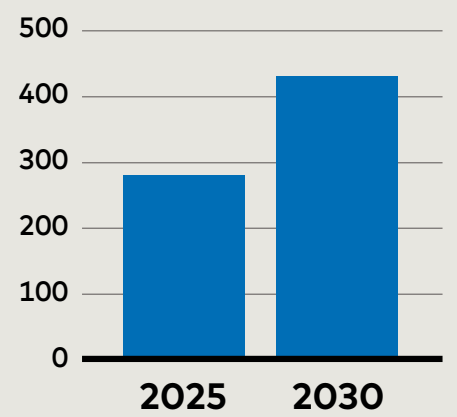

Emissions reduction potential 430 $\mathrm{MtCO}_{2} \mathrm{e} /$ year

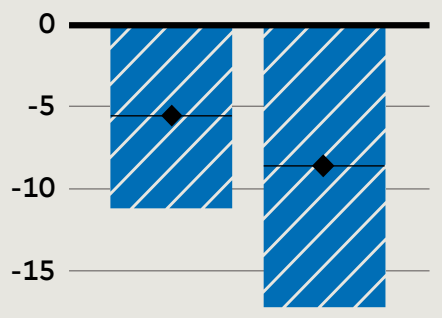

Total abatement costs

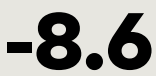

billion \$

20252030 


\title{
Residential heat pumps
}

\author{
Sweden provides a noticeable and increasing share \\ of its heat with heat pumps. Scaling up the solution \\ to selected European countries would cut emissions \\ by as much as Cuba produces every year, \\ while improving energy security.
}

\section{Climate impact}

In 2014, heat pumps in Sweden delivered 14 TWh of heat. This translates into $1 / 5$ of the total space and water heating demand. The annual growth since 2005 has been $8.4 \%$.

Scaling up the solution to selected European countries would increase energy provided with heat pumps by almost 400 TWh above the baseline in 2030 . Taking into account the emissions from powering the pumps, this would result in an emission reduction of $64 \mathrm{Mt}$ in 2030. The impact may seem small as the target countries are expected to increase the use of heat pumps already in the baseline.

\begin{tabular}{|l|ccc|ccc|} 
& \multicolumn{3}{|c|}{2025} & \multicolumn{3}{c|}{2030} \\
& Lower & Central & Upper & Lower & Central & Upper \\
\hline $\begin{array}{l}\text { Reduction } \\
\text { potential } \\
\text { MtCO }\end{array}$ & 12 & 19 & 22 & 47 & 64 & 72 \\
\hline
\end{tabular}

\section{Success factors}

Heat pumps allow for more efficient heating by taking heat energy from outside and with the help of electrical work pumping that energy indoors as heat, effectively acting as a refrigerator in reverse. Heat pumps can save energy by providing 2-4 units of heat for each unit of electricity used.

Most Nordic countries excel in installing heat pumps for residential heating. Sweden has had the world's highest number of heat pumps per population.

In the early 1990s Sweden launched a wellcoordinated programme with activities on testing, certification, subsidies and information. The focus was on knowledge development, networking and market formation, but also on quality control, credibility and legitimacy.

The Swedish Energy Agency (SEA) has had a big role in supporting this development, mainly through its financial support for the Effsys and Effsys2 research programmes. Between 1975 and 2008 the government invested around SEK 200 million in heat pump R\&D.

SEA has been testing heat pumps since 2004 to help consumers to choose a product that best fits their needs regarding energy efficiency, noise levels, price and quality. The webpage presenting test results of heat pumps had about 366,000 visits in 2014 alone.

The programme boosted demand for heat pumps with sales doubling from 1995 to 1996 . Between 1996 and 2006 the number of installations increased at an average of $35 \%$ per year. During the past three decades, costs have been reduced by more than a factor two. Today, heat pumps are cost-competitive with fossil fuels. Important drivers of the cost reduction have been the economies of scale for heat pumps and borehole drilling as well as continuous technology improvements.

\section{Costs}

Retrofitting residential heat pumps come at a negative abatement cost of $-52 \$ / \mathrm{tCO}_{2}$. Scaling up the solution would result in total costs of $-\$ 3.2$ billion in 2030 .

\begin{tabular}{|l|ccc|ccc|} 
& \multicolumn{3}{|c|}{2025} & \multicolumn{3}{c|}{2030} \\
& Lower & Central & Upper & Lower & Central & Upper \\
\hline $\begin{array}{l}\text { Total } \\
\text { costs } \\
\text { billion \$ }\end{array}$ & -0.6 & -0.9 & -1.1 & -2.3 & $-\mathbf{3 . 2}$ & -3.6 \\
\hline
\end{tabular}




\title{
Bioenergy for heating
}

\author{
Finland provides a large share of heat for buildings with \\ bioenergy. Scaling up this solution to other countries \\ with a cold climate and large biomass resources \\ would cut global emissions by more than Bangladesh \\ produces every year, while creating local jobs.
}

\section{Climate impact}

In Finnish buildings, the direct use of biomass accounted for $28 \%$ of final energy use other than electricity. In total, bioenergy is estimated to save approximately 6.8 Mt of emissions in Finland annually.

We have extended the same share of bioenergy in buildings to other countries with both cold climates and sufficient biomass resources: Russia, Canada and Mongolia. This would result in an emission reduction of $193 \mathrm{Mt}$ in 2030.

\begin{tabular}{|l|ccc|ccc|} 
& \multicolumn{3}{|c|}{2025} & \multicolumn{3}{c|}{2030} \\
& Lower & Central & Upper & Lower & Central & Upper \\
\hline $\begin{array}{l}\text { Reduction } \\
\text { potential } \\
\mathrm{MtCO}_{2} \mathrm{e}\end{array}$ & 159 & 187 & 215 & 164 & 193 & 222 \\
\hline
\end{tabular}

\section{Success factors}

Cold climates combined with widespread forests and large forestry industries make biomass in the form of wood residues a natural source of energy in Finland, Sweden and Norway. Finland stands out specifically due to its large forestry sector and high share of bioenergy in heating.

Biomass plays a large and growing role in the Finnish energy system. Biomass (mostly in the form of wood residues and pellets) accounted for $20 \%$ of total final energy consumption in the country in 2013, as well as for over $40 \%$ of commercial heat generation.

In Finland, bioenergy has been relatively attractive in many cases purely on commercial terms. Forestry companies have tried to find ways to turn their waste and by-products into profit-making products.
There are also three different subsidies for biomass use in general. A feed-in tariff for electricity produced from wood chips is linked to the allowance prices in the EU emissions trading system. A separate feed-in tariff is provided for small wood-burning CHP plants. Finally, the energy use of small-diameter wood from young forests is also subsidised.

\section{Costs}

Costs for bioenergy may vary significantly. We have derived the upper end for the cost range from the estimated abatement costs for Russia. As a lower bound, it is assumed that the solution can be implemented at no extra cost. This would result in an estimated total cost of $\$ 7.7$ billion in 2030 .

\begin{tabular}{|l|ccc|ccc|} 
& \multicolumn{3}{|c|}{2025} & \multicolumn{4}{c|}{2030} \\
& Lower & Central & Upper & Lower & Central & Upper \\
\hline $\begin{array}{l}\text { Abatement } \\
\text { costs } \\
\$ / \mathrm{tCO}_{2} \mathrm{e}\end{array}$ & 0 & 40 & 80 & 0 & 40 & 80 \\
\hline $\begin{array}{l}\text { Total } \\
\text { costs } \\
\text { billion } \$\end{array}$ & 0 & $\mathbf{7 . 7}$ & 15.0 & 0 & 7.7 & 15.5 \\
\hline
\end{tabular}

\section{Co-benefits}

Increasing the use of bioenergy for heating can provide some co-benefits, including

- reducing fuel imports

- improving energy security

- creating local jobs 


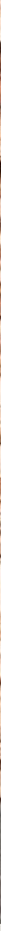

\section{Barriers and drivers}

Like other solutions relying on biomass, increasing the share of bioenergy relies on the availability of sustainable biomass (see page 21). Too large or poorly planned increases in the use of bioenergy can have adverse impacts on ecosystems or food production, if biodiverse forests or agricultural lands are harnessed. However, the three target countries have similar amounts of wood residue per capita as Finland. They should therefore be able to reach Finland's level of bioenergy use without additional biomass extraction.

The most economic use of biomass for heating is through district heating and combined heat and power production, which both require significant investment to build infrastructure. The necessary investment can be facilitated with several policies (see page 32).

In many cases, forestry companies already have a financial incentive to provide their waste wood for heating. The main enabler may be to ensure that market and infrastructure conditions are right to absorb large amounts of biomass into the heating systems. Constructing district heating will be an important enabler where possible, since this allows for a more flexible use of fuels than local burners in each home.

\section{Bioenergy already covers $20 \%$ of all energy needs in Finland.}
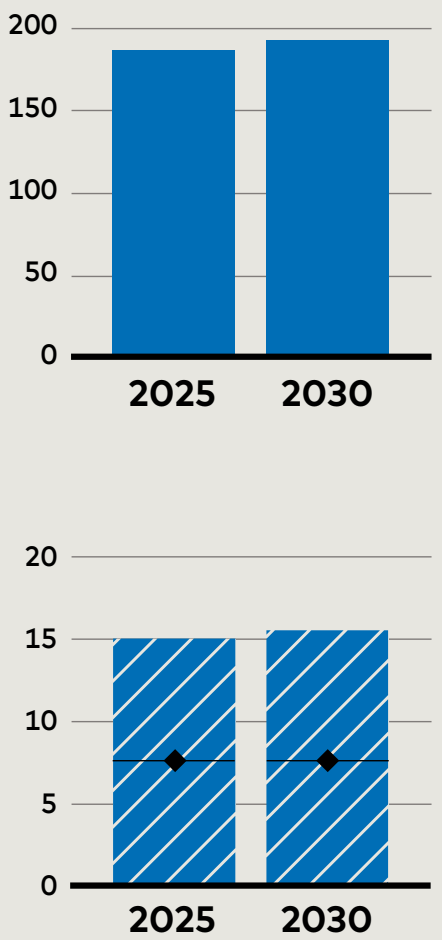

Total abatement costs 7.7 billion $\$$ 


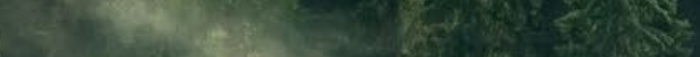

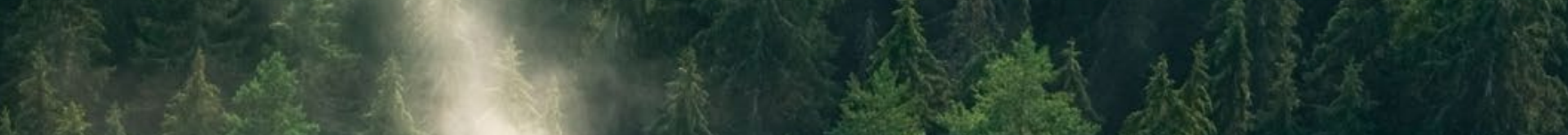

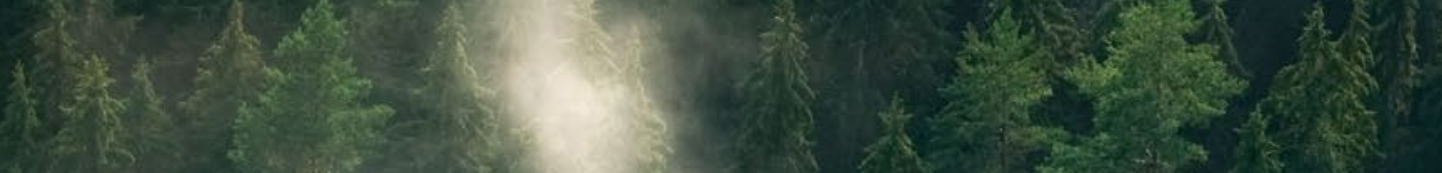

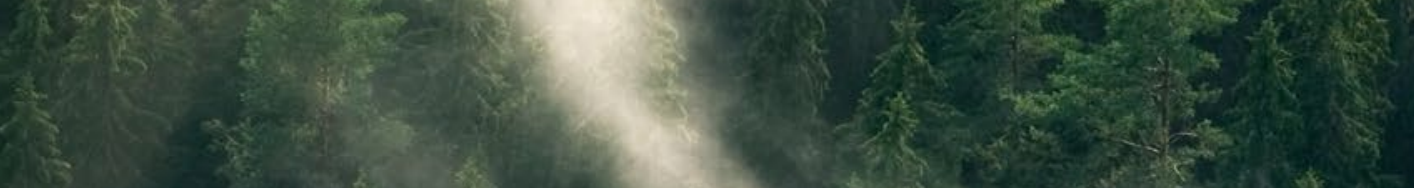

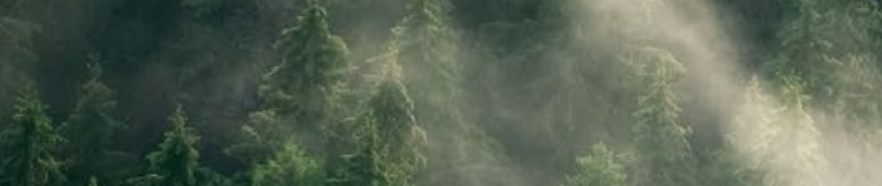

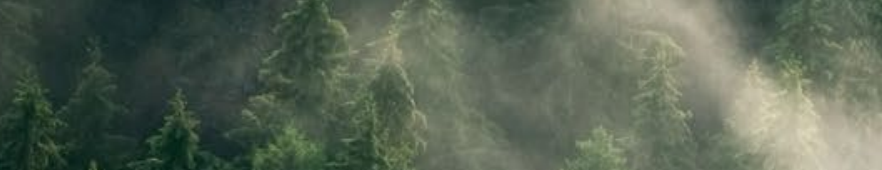

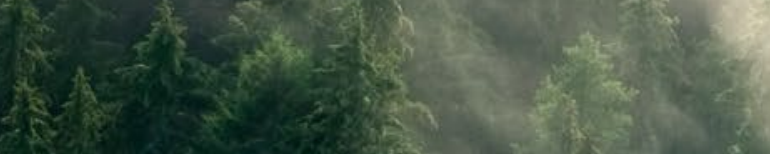
8y $1 \times 35$

(5)

istis

3050 .

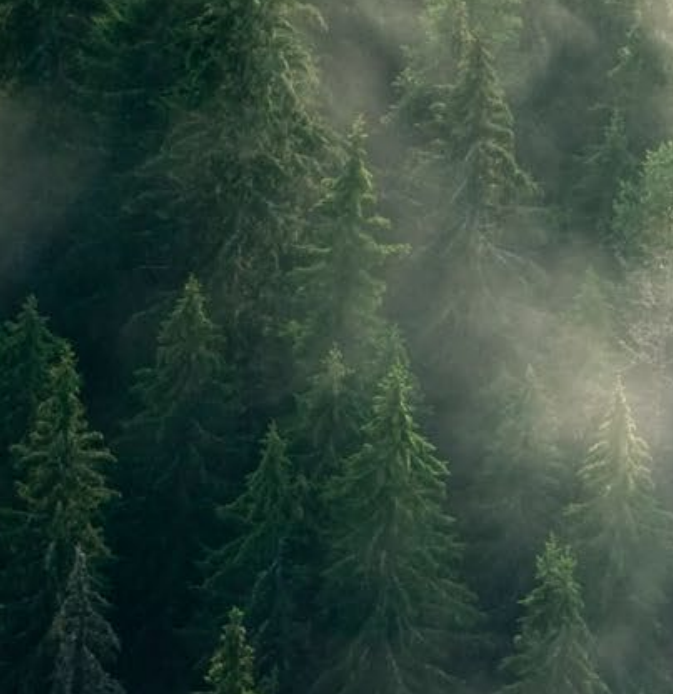

$$
\begin{aligned}
& \text { 2. } \\
& \text { s. }
\end{aligned}
$$$$
\text { 4t: }
$$

thes

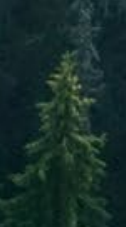




\section{AGRICULTURE AND FORESTS}

Reforestation and land restoration

Manure management 


\title{
AGRICULTURE AND FORESTS
}

\section{Reforestation and land restoration}

\author{
Iceland has been able to reforest and restore lost vegetation. \\ Scaling up the solution to other temperate countries would \\ reduce global emissions by almost as much as Panama produces \\ every year, while providing valuable ecosystem services.
}

\section{Climate impact}

Iceland has converted $470 \mathrm{~km}^{2}$ of non-forested land to forest, which constitutes an estimated $1.4 \%$ of the land area covered by woods before human settlement in the country. The carbon sink represented by this added forest land is approximately $265 \mathrm{ktCO}_{2}$ per year.

There is significant potential for afforestation and restoration of degraded lands in the mostly temperate western industrialised countries and former Eastern Bloc countries. If these countries were to reach the Icelandic degree of implementation, this would reduce global emissions by $21 \mathrm{Mt}$ in 2030 .

\begin{tabular}{|l|ccc|ccc|}
\hline & \multicolumn{3}{|c|}{2025} & \multicolumn{3}{|c|}{2030} \\
\hline & Lower & Central & Upper & Lower & Central & Upper \\
\hline $\begin{array}{l}\text { Reduction } \\
\text { potential } \\
\text { MtCO }_{2} \mathrm{e}\end{array}$ & 11 & 12 & 13 & 20 & 21 & 23 \\
\hline
\end{tabular}

\section{Success factors}

Iceland has very little forest cover and large parts of the country are sparsely vegetated. Around 30\% of the country was covered by natural woodlands as the country was settled in the late 9th century, but most of it disappeared within the first two centuries of human habitation. Similarly, as much as $40 \%$ of the land is believed to have been degraded by soil and vegetation loss after settlement.

Iceland has conducted systematic reforestation efforts after the Second World War. The efforts were ramped up with 4-5 times as many seedlings planted per year in the 1990 s and early 2000 s. The rate of afforestation decreased considerably after the 2008 financial crisis, but has still been significantly higher than before the 1990s.

Mos t reforestation has taken place through state support for the afforestation on farms and other privately owned land. Current Icelandic policies aim for the afforestation of at least $5 \%$ of all land located less than 400 metres above sea level with various regional projects.

Iceland also has an extensive programme to battle soil erosion and reclaim and restore degraded land. The Soil Conservation Service of Iceland was founded for this purpose and a land restoration training programme was launched in 2007. In addition, there is increasing focus on restoring wetlands that have previously been drained for pasture and agriculture.

\section{Costs}

We have used abatement costs of $17.0 \$ / \mathrm{tCO}_{2}$ for reforestation and $12.4 \$ / \mathrm{tCO}_{2}$ for degraded land restoration, with a weighted average of $16.2 \$ / \mathrm{tCO}_{2}$. The resulting total abatement cost is $\$ 339$ million in 2030.

\begin{tabular}{|l|ccc|ccc|}
\hline & \multicolumn{3}{|c|}{2025} & \multicolumn{3}{c|}{2030} \\
& Lower & Central & Upper & Lower & Central & Upper \\
\hline $\begin{array}{l}\text { Total } \\
\text { costs } \\
\text { million \$ }\end{array}$ & 183 & 198 & 215 & 315 & 339 & 369 \\
\hline
\end{tabular}




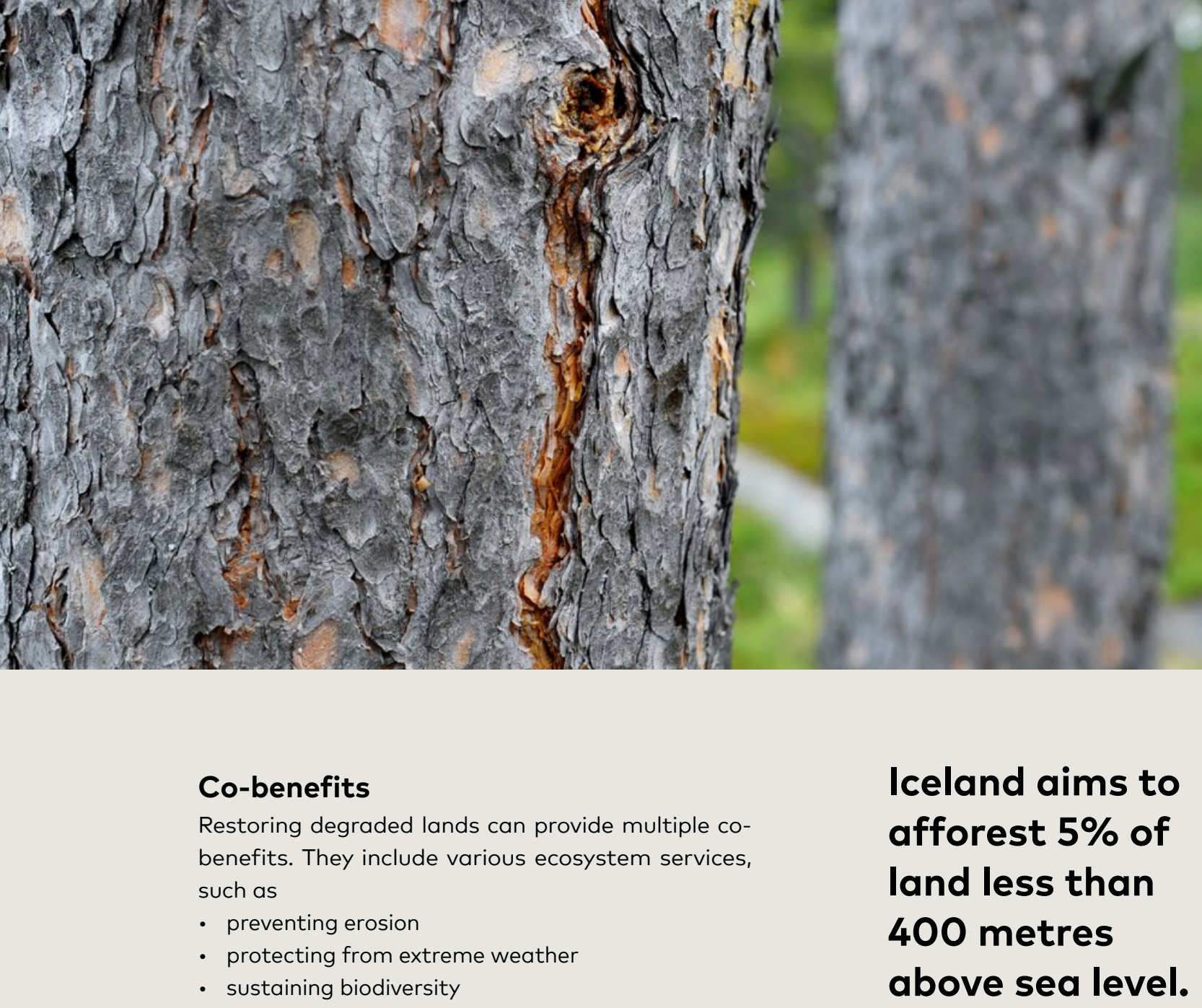

\section{Barriers and drivers}

The greatest barriers to reforestation are likely to be alternative land uses with higher perceived economic value. In particular, any measure which requires encroaching on crop land or pastures may face opposition. Programmes can address the issue by primarily targeting degraded lands, which typically have little economic value in their current state.

Since reducing soil erosion is likely to benefit local land owners in the medium and long-term, information campaigns may be important. Further, economic compensation for reforestation and payments based on the amount of standing biomass will help, if land owners do not already have a financial incentive to plant trees or vegetation. An example of pioneering incentives for land owners is the payment for ecosystem services system in Costa Rica.

In the relatively developed target countries, large-scale illegal logging and other contravention of government policies are unlikely to be a major problem. If the solution were extended to developing countries, measures would need to be introduced to ensure monitoring and enforcing policies.

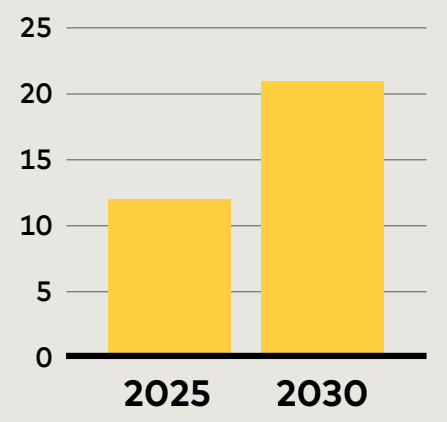

Emissions reduction potential 21 $\mathrm{MtCO}_{2} \mathrm{e} /$ year

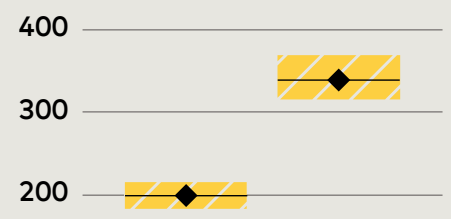

100

Total abatement costs 339

million \$ 


\title{
AGRICULTURE AND FORESTS
}

\section{Manure management}

\author{
Denmark has been able to reduce emissions from \\ manure considerably. Scaling up the solution to \\ other countries would cut emissions by more than \\ Nigeria produces every year, while protecting \\ waterways from pollution.
}

\section{Climate impact}

Denmark has reduced nitrous oxide $\left(\mathrm{N}_{2} \mathrm{O}\right)$ emissions from agriculture by almost 30\% between 1990 and 2014. As the agricultural area decreased by approximately only $4 \%$ during the same time, we see an emission efficiency improvement of $28 \%$.

Similar measures to cut $\mathrm{N}_{2} \mathrm{O}$ emissions can also be taken in other countries. Scaling up the solution would reduce emissions by $478 \mathrm{Mt}$ in 2030, converted into $\mathrm{CO}_{2}$ equivalents.

\begin{tabular}{|l|ccc|ccc|}
\hline & \multicolumn{2}{|c|}{2025} & \multicolumn{3}{c|}{2030} \\
& Lower & Central Upper & Lower & Central Upper \\
\hline $\begin{array}{l}\text { Reduction } \\
\text { potential } \\
\text { MtCO }_{2} \mathrm{e}\end{array}$ & 253 & 269 & 284 & 450 & 478 & 506 \\
\hline
\end{tabular}

\section{Success factors}

$\mathrm{N}_{2} \mathrm{O}$ emissions in Denmark have declined over time due to strict regulations on fertiliser and manure management. The main driver has been the EU Nitrate Directive protecting water from nutrient runoff.

One part of the solution is to control how and when manure spreading is allowed. In Denmark animal manure must be tilled into the soil within six hours. It is not allowed for the fertiliser to spread into drains and streams. Application onto black soil and permanent grass must be done by injection or pretreated slurry. The manure used may not exceed the amount from 2.3 livestock units per hectare.

The second part of requirements is on storage and use. Slurry containers cannot be located less than 100 metres from the nearest stream or lake, they must be made of durable materials and need to be covered. Finally, various crops have nitrogen standards on how much fertiliser can be applied.

\section{Costs}

The abatement cost for similar measures in Iceland has been estimated at $5 \$ / \mathrm{tCO}_{2} \mathrm{e}$. The total cost of implementing the solution would then be $\$ 1.33$ billion in 2025 and $\$ 2.37$ billion in 2030 . 


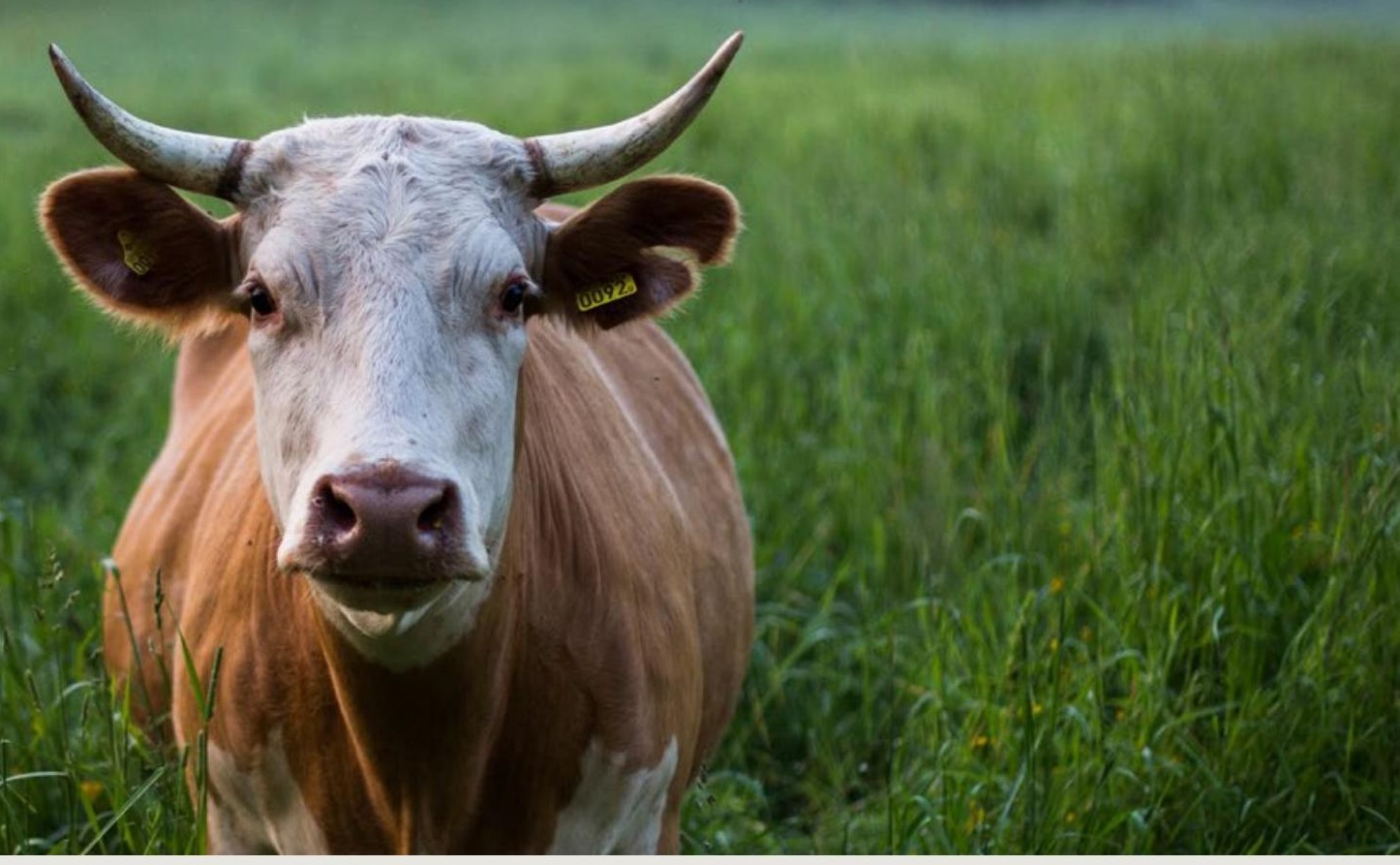

\section{Co-benefits}

The main driver for manure management are cobenefits, especially reducing water pollution.

\section{Barriers and drivers}

This solution is policy-driven, as seen in Denmark. Scaling it up to other countries would require stringent requirements, in particular those regarding water quality. Substantial policy interventions into farming practices may be politically difficult in some countries.

Monitoring compliance at farms may not be possible in many cases. Particularly poorer countries might need support to build their capacity to execute and follow the regulations.

\section{Denmark has improved the $\mathrm{N}_{2} \mathrm{O}$ emission efficiency of agriculture by almost $30 \%$.}
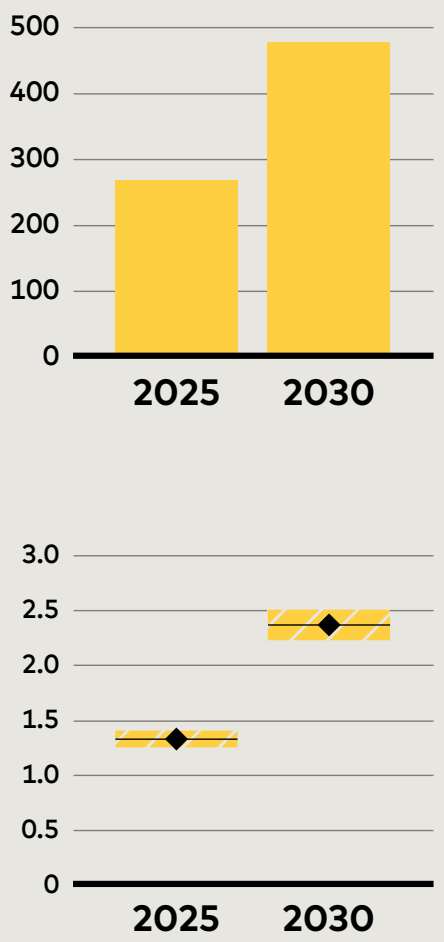

Emissions reduction potential 478 $\mathrm{MtCO}_{2} \mathrm{e} /$ year
Total abatement costs

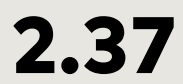

billion \$ 
Annex: Target countries for solutions

\begin{tabular}{|c|c|c|}
\hline Category & Solution & Scaled up to \\
\hline \multirow{4}{*}{ Energy } & Combined heat and power production & $\begin{array}{l}\text { 1) Industrial CHP: world } \\
\text { 2) District heating: urban areas in OECD countries }\end{array}$ \\
\hline & Onshore wind power & World \\
\hline & Offshore wind power & $\begin{array}{l}\text { North America, OECD Europe, } \\
\text { Asia and Oceania }\end{array}$ \\
\hline & Geothermal power & World \\
\hline \multirow{3}{*}{ Industry } & $\begin{array}{l}\text { Carbon capture and storage in oil } \\
\text { and gas production }\end{array}$ & $\begin{array}{l}\text { Relatively wealthy oil- and gas-producing } \\
\text { countries }\end{array}$ \\
\hline & Reducing methane in oil and gas production & $\begin{array}{l}\text { Russia, select countries in the Middle East and } \\
\text { Southeast Asia, Colombia, Mexico and Venezuela }\end{array}$ \\
\hline & Low-carbon energy in industry & World \\
\hline \multirow{3}{*}{ Transport } & Electric vehicles & OECD, Brazil and China \\
\hline & Biofuels in transport & World \\
\hline & Cycling in cities & Urban areas globally \\
\hline \multirow{3}{*}{$\begin{array}{l}\text { Buildings and } \\
\text { households }\end{array}$} & Energy efficiency in buildings & EU, USA and Japan \\
\hline & Residential heat pumps & $\begin{array}{l}\text { Western Europe, Visegrad countries, Estonia and } \\
\text { Lithuania }\end{array}$ \\
\hline & Bioenergy for heating & Canada, Mongolia and Russia \\
\hline \multirow{2}{*}{$\begin{array}{l}\text { Agriculture } \\
\text { and forests }\end{array}$} & Reforestation and land restoration & Industrialised countries \\
\hline & Manure management & World \\
\hline
\end{tabular}

For a full and exact list of target countries, please refer to the technical report (available at www.greentoscale.net/nordic). 

Nordic Council of Ministers

Ved Stranden 18

DK-1061 Copenhagen K

Phone (+45) 33960200

\section{Nordic Green to Scale}

2015 was a year of commitments. From now on every year has to be a year of action. To achieve the goals set in the Paris agreement countries need to ramp up their climate efforts significantly. And we need to do it fast.

The Finnish Innovation Fund Sitra has teamed up with the Nordic Council of Ministers and distinguished institutions from all other Nordic countries to answer a simple question: how far could we go simply by scaling up existing Nordic low-carbon solutions internationally.

This study shows that there are already plenty of proven low-carbon solutions available, and at an affordable cost. There is no reason to wait. The time to deliver is now. 